\title{
Intakes of nutrients and food categories in Canadian children and adolescents across levels of sugars intake: cross-sectional analyses of the Canadian Community Health Survey 2015 Public Use Microdata File
}

\author{
Laura Chiavaroli, Ye (Flora) Wang, Mavra Ahmed, Alena (Praneet) Ng, Chiara DiAngelo, Sandra Marsden, \\ and John L. Sievenpiper
}

\begin{abstract}
Dietary recommendations to reduce sugars consumption may influence choices of sugars-containing foods and affect the intake of key micronutrients. We compared intakes of nutrients and food sources stratified by quintiles of total sugars in Canadian children (2-8 y) and adolescents (9-13 y, 14-18 y) using 24-hour dietary recalls from the 2015 Canadian Community Health Survey-Nutrition. Energy intakes did not differ across quintiles of sugars intake. Those with lower sugars intakes $(\mathrm{Q} 1 / \mathrm{Q} 3)$ generally had higher protein, fat, sodium, niacin, folate, and zinc and lower vitamin C compared with those with the highest sugars intakes (Q5). Q1 also had lower potassium but higher saturated fat compared with Q5. Further, Q1 generally had higher protein, fats, and niacin compared with Q3, while children in Q3 had higher potassium and riboflavin and older adolescents had higher calcium and fibre. Q5 had highest intakes of multiple sugar-containing food categories (e.g., fruit, confectionary, milks, cakes/pies/pastries), with higher sugars-sweetened beverages in adolescents. Q3 had higher fruit, milks, and fruit juice compared with Q1 and lower sugars/syrups/preserves, confectionary, and fruit juices compared with Q5. Certain nutrient-dense food sources of sugars (fruit, milks) may help increase key nutrients (potassium, calcium, fibre) in older adolescents with low sugars intakes. However, in those with the highest sugars intakes, nutrientpoor foods may displace nutrient-dense foods.
\end{abstract}

Novelty:

- Canadian children and adolescents with lower sugars intake have better intakes of some nutrients.

- Energy intakes did not differ across sugars intake.

- Older adolescents with mean intakes of total sugars had better intakes of some key nutrients (potassium, calcium, fibre).

Key words: total sugars, added sugars, free sugars, consumption, Canadian, children, adolescents, cross-sectional, nutrients, food categories.

Résumé : Les recommandations diététiques visant à réduire la consommation de sucre peuvent influencer les choix d'aliments contenant des sucres et affecter l'apport en micronutriments clés. Nous avons comparé les apports en nutriments et les sources alimentaires stratifiés par quintiles de sucres totaux chez les enfants $(2$ à 8 ans) et les adolescents canadiens $(9$ à 13 ans, 14 à 18 ans) en utilisant des rappels alimentaires de 24 heures de l'Enquête sur la santé dans les collectivités canadiennes - Nutrition 2015. Les apports énergétiques ne différaient pas entre les quintiles d'apport en sucre. Les individus présentant des apports en sucre inférieurs $(\mathrm{Q} 1 / \mathrm{Q} 3)$ présentaient généralement des protéines, des lipides, du sodium, de la niacine, du folate et du zinc plus élevés et une vitamine $C$ plus faible que ceux présentant les apports en sucre les plus élevés (Q5). Le groupe Q1 présentait également moins de potassium mais plus de graisses saturées par rapport au Q5. De plus, les individus de Q1 présentaient généralement plus de protéines, de graisses et de niacine par rapport au Q3, tandis que les enfants de Q3 présentaient plus de potassium et de riboflavine et les adolescents plus âgés présentaient plus de calcium et

Received 27 July 2021. Accepted 15 December 2021.

L. Chiavaroli. Departments of Nutritional Sciences and Medicine, Temerty Faculty of Medicine, University of Toronto, Toronto, ON M5B 1W8, Canada; Toronto 3D Knowledge Synthesis and Clinical Trials Unit, Clinical Nutrition and Risk Factor Modification Centre, St. Michael's Hospital, Toronto, ON M5B 1W8, Canada.

Y.(F.) Wang, C. DiAngelo, and S. Marsden. Nutrition Information Service, Canadian Sugar Institute, Toronto, ON M5V 3E4, Canada.

M. Ahmed. Departments of Nutritional Sciences and Medicine, Temerty Faculty of Medicine, University of Toronto, Toronto, ON M5B 1W8, Canada; Joannah and Brian Lawson Centre for Child Nutrition, Temerty Faculty of Medicine, University of Toronto, Toronto, ON M5S 1A8, Canada. A.(P.) Ng. Departments of Nutritional Sciences and Medicine, Temerty Faculty of Medicine, University of Toronto, Toronto, ON M5B 1W8, Canada. J.L. Sievenpiper. Departments of Nutritional Sciences and Medicine, Temerty Faculty of Medicine, University of Toronto, Toronto, ON M5B 1W8, Canada; Toronto 3D Knowledge Synthesis and Clinical Trials Unit, Clinical Nutrition and Risk Factor Modification Centre, St. Michael's Hospital, Toronto, ON M5B 1W8, Canada; Li Ka Shing Knowledge Institute, St. Michael's Hospital, Toronto, ON M5B 1W8, Canada; Division of Endocrinology and Metabolism, St. Michael's Hospital, Toronto, ON M5B 1W8, Canada.

Corresponding author: Laura Chiavaroli (email: laura.chiavaroli@alumni.utoronto.ca).

() 2022 The Author(s). This work is licensed under a Creative Commons Attribution 4.0 International License (CC BY 4.0), which permits unrestricted use, distribution, and reproduction in any medium, provided the original author(s) and source are credited. 
de fibres. Les individus de Q5 présentaient les apports les plus élevés dans plusieurs catégories d'aliments contenant du sucre (par exemple, fruits, confiseries, laits, gâteaux/tartes/pâtisseries) et, chez les adolescents, plus de boissons sucrées. Les individus de Q3 présentaient plus de fruits, de laits et de jus de fruits par rapport au Q1 et moins de sucres/sirops/conserves, de confiseries et de jus de fruits par rapport au Q5. Certaines sources alimentaires riches en nutriments et en sucre (fruits, laits) peuvent aider à augmenter l'apport en nutriments clés (potassium, calcium, fibres) chez les adolescents plus âgés ayant un faible apport en sucre. Cependant, chez les individus qui ont les apports en sucre les plus élevés, les aliments pauvres en nutriments peuvent remplacer les aliments riches en nutriments. [Traduit par la Rédaction]

\section{Les nouveautés :}

- Les enfants et les adolescents canadiens présentant une faible consommation de sucre ont de meilleurs apports de certains nutriments.

- Les apports énergétiques ne différaient pas selon l'apport en sucre.

- Les adolescents plus âgés présentant des apports moyens en sucres totaux avaient de meilleurs apports en certains nutriments clés (potassium, calcium, fibres).

Mots-clés : sucres totaux, sucres ajoutés, sucres libres, consommation, Canadiens, enfants, adolescents, transversal, nutriments, catégories d'aliments.

\section{Introduction}

Childhood obesity rates have doubled over the last 4 decades (Rao et al. 2016), exposing over 30\% (Pan-Canadian Public Health Network 2017; Rao et al. 2016) of Canadian children and adolescents to elevated risks of chronic diseases, such as cardiovascular disease and type 2 diabetes (Morrison et al. 2007; Must et al. 1992; Public Health Agency of Canada 2011). The complex etiology of obesity and its global epidemic has driven research advancement and dietary guideline development, many of which have focused on nutrients of concern, such as saturated fat, sodium, and sugars, and corresponding foods to limit in the diet. With regards to sugars, excess consumption of sugars, particularly sugars-sweetened beverages, has been a key focus in relation to these chronic conditions (Stanhope 2016; Malik et al. 2010). Many organizations globally recommend limiting the intake of sugars. For example, the World Health Organization (WHO) advocates for limiting intake of free sugars to $<10 \%$ of total energy intake (\%E), based primarily on observational studies in relation to dental caries (WHO 2015).

Concerns over the link between sugars and body weight in children have largely been derived from data on sugars-sweetened beverages from prospective cohort studies, which demonstrate that children with the highest intakes of sugars-sweetened beverages have a greater likelihood of being overweight or obese than children with the lowest intakes (Te Morenga et al. 2012). Evidence from systematic reviews and meta-analyses of randomized controlled trials in children looking at sugars-sweetened foods and beverages reduction have shown no overall change in standardized body mass index; however, these findings should be interpreted with caution as they were seriously limited by generally low compliance to dietary advice (Te Morenga et al. 2012). Other foods in the diets of children and adolescents, such as milks, yogurts, and fruits and vegetables, despite contributing sugars, have been shown to support key roles in growth and development, as well as in maintaining a healthy body weight and reducing the risk of noncommunicable diseases (WHO 2019; Mytton et al. 2014; Givens 2020; Berkey et al. 2009). These foods are also major sources of key nutrients in the diet, including potassium, fibre, calcium, and phosphorus, which Health Canada highlights as micronutrients of public health concern related to inadequate intake in Canadian children and adolescents (Health Canada 2012a, 2012b).

Based on the 2015 and 2004 iterations of the Canadian Community Health Survey (CCHS) (2015 CCHS-Nutrition and 2004 CCHSNutrition), Statistics Canada demonstrated that over the past decade, intakes of sugars from beverages have decreased while intakes from foods have increased. Overall, the average intake of total sugars has been stable in the Canadian population, when accounting for misreporting (Langlois et al. 2019). Uncertainty remains as to whether food choices altered primarily based on sugars content, may unintentionally result in changes in Canadian intakes of some nutrient-dense, sugars-containing foods. A recent analysis of 2015 CCHS-Nutrition in adults demonstrated that those with moderate intakes of total sugars had greater intakes of dietary fibre, calcium, potassium, and vitamins A, C, and D compared with those with lower sugars intakes. These higher vitamin and mineral intakes among adults with moderate sugars intake principally resulted from higher intakes of fruit, milks, and yogurts (Wang et al. 2020). However, this has yet to be explored in Canadian children and adolescents.

The objective of the present study was to assess the consumption of sugars (total, added, and free) in the diets of Canadian children and adolescents and compare the intakes of food categories, as well as macro- and micronutrients, across the spectrum of total sugars intakes, using the 2015 CCHS-Nutrition Public Use Microdata Files (PUMF).

\section{Materials and methods}

\subsection{Data source and respondents}

The 2015 CCHS-Nutrition is the most recent cross-sectional, nationally representative survey of nutrition conducted by Statistics Canada from January to December 2015, the details of which have been published (Statistics Canada 2017). The survey included a 24-hour dietary recall that was administered in-person by trained interviewers using a computerized modification of the U.S. Department of Agriculture (USDA) Automated Multiple-Pass Method (USDA 2019). The initial recall was completed by 20487 people living in the 10 Canadian provinces. An in-person interviewer-administrated general health questionnaire also collected sociodemographic, anthropometric, and health status data.

The sampling strategy, as previously described (Statistics Canada 2017; Wang et al. 2020), was designed to provide a sample representative of the Canadian population by age, sex, geography, and socioeconomic status. For children aged $2-5 y$, interviews were conducted with a parent or guardian only (a "proxy interview"). For those aged 6-11 y, both the child and parent or guardian were interviewed. For those aged 12-18 y, the interview was conducted with the adolescent only. If a child $>6 \mathrm{y}$ had a mental or physical health limitation that did not allow for an interview, then a proxy interview was conducted. Further information on data acquisition for children and adolescents in the 2015 CCHS-Nutrition can be found in the reference guide (Health Canada 2017). Foods and beverages reported in the 24-hour dietary recall were coded by Health Canada using the 2015 Canadian Nutrient File and Health Canada Bureau of Nutritional Science (BNS) food codes (Health Canada 2015, 2017).

For the present analysis on data for children and adolescents (2-18 y), we followed a similar methodology previously published (Wang et al. 2020). We used data from the 2015 CCHS-Nutrition 
PUMF (Statistics Canada 2018), including data from the first 24-hour dietary recall and health information from the general health questionnaire (height, weight, and self-reported physical activity). The 2015 CCHS-Nutrition PUMF are publicly accessible through Health Canada and contain the same information that can be found in the Statistics Canada-restricted Master files. Respondents were excluded if they had invalid dietary recalls (Statistics Canada 2015) or did not have relevant information to adjust for misreporting (Garriguet 2018). Supplemental Fig. S1 ${ }^{1}$ represents the sample selection process, which identified data available from children and adolescents ( $n=5491,2-18$ y). Analyses were performed separately for those aged 2-8 y $(n=1896)$, 9-13 y $(n=1842)$, and $14-18$ y $(n=1453)$.

\subsection{Estimation of added and free sugars}

The 10-step decision algorithm by Louie et al. (2015) was used to estimate added, and free sugars intakes for each participant. The definition of added sugars included sugars, and syrups added to foods by manufacturers or consumers. The WHO definition of free sugars was used, which included sugars added to foods by manufacturers or consumers, and those naturally present in honey, syrups, and fruit juices. Free sugars therefore included both added sugars and sugars found in $100 \%$ fruit juices. For each BNS food code $(n=177)$, added and free sugars were assigned according to the 10-step algorithm (Louie et al. 2015). The majority were determined objectively (steps 1-6 in Louie et al. 2015); approximately $6 \%$ were determined more subjectively using other available data, assumptions and estimates (steps 7-10 in Louie et al. 2015). Fruits, vegetables, and unsweetened milks had all sugars assigned as naturally occurring. Confectionary, sugars and syrups, fruit drinks, baked goods and products, and frozen desserts had all sugars assigned as added. For foods such as sweetened yogurts, which contain both naturally occurring and added sugars, the amount of added sugars was assigned by determining the difference between the total sugars in the sweetened version compared with the unsweetened counterpart.

\subsection{Adjusting for misreporting}

Misreporters (those over- or underreporting energy intake) were identified by comparing reported energy intakes (EI) with total energy expenditure (TEE), based on the method by Garriguet (2018). The TEE of respondents were based on age, sex, height, weight, and physical activity levels based on the Institute of Medicine equations (Institute of Medicine 2005) when measured height and weight were available; otherwise, USDA definitions were used to assign TEE by age, sex, and physical activity level (United States Department of Health and Human Services and United States Department of Agriculture 2016). Physical activity levels for adolescents aged 14-18 y were coded as sedentary and those aged $\leq 13$ y were coded as lowactive (Garriguet et al. 2016; Colley et al. 2017). The ratio of EI:TEE was used to identify underreporting at $<0.7$ and overreporting at $>1.42$. All analyses included the resulting misreporting variable as a covariate.

\subsection{Statistical analyses}

Analyses were conducted using SAS version 9.4 (SAS Institute) using survey weights provided by Statistics Canada to ensure nationally representative findings. As previously described (Wang et al. 2020), all measures of variance were estimated using bootstrap balanced repeated replication with 500 replicates. To account for energy intake, nutrients were either expressed as a percentage of total energy (\%E) or per $1000 \mathrm{kcal}$. The intake distribution of all nutrients was transformed to approximate normality using the Box-Cox transformation method (Bilodeau and Brenner 1999; Brisbois et al. 2014) to satisfy normality requirements of statistical tests. Food category variables were identified using BNS codes and expressed as weighted averages (grams/day) (Supplementary Table S1 ${ }^{1}$ ).

Total, free, and added sugars intakes were reported for Canadian children aged 2-8 y, young adolescents aged 9-13 y, and older adolescents aged 14-18 y. Each age subgroup was divided into evenly distributed quintiles $(\mathrm{Q})$ based on intakes of total sugars as \% $\mathrm{E}$, to assess and compare the intakes of food categories and nutrients across quintiles. The ANOVA method, with multiple comparisons adjusted for using the post hoc Bonferroni correction (PROC SURVEYREG), was used to perform covariate-adjusted comparisons between quintiles of total sugars intake and food categories or nutrients. Analyses were conducted using 3 covariate-adjusted models. All analyses were first performed using Model 1, including misreporting status as a covariate. In the analyses of food categories, Model 2 adjusted for misreporting status, sex, immigrant status, weekend reference day, and energy intake. In the analyses of nutrients, Model 3 included the same adjustments as in Model 2 with the exception of energy intake (as nutrient variables were already adjusted). Covariates were chosen from the literature and selected for inclusion in the models based on a backwards stepwise regression selection model. Within each age group assessed, neither age, income, nor self-perceived health were included as these were not significant in the stepwise regression. Body mass index (BMI) and age- and sex-specific BMI cut-offs to classify children's BMI were identified in PUMF based on the values from the growth curves for specific reference populations. The PUMF included BMI reported using both WHO (WHO 2006) and International Obesity Task Force cut-offs (Cole et al. 2000). Neither of these self-reported or measured BMI variables were significant in the regression models across age groups. Thus, BMI was not included as a covariate. Results from the most-adjusted model are presented, with statistical significance set at $p<0.05$.

\section{Results}

\subsection{Sample characteristics}

The sample evenly represented boys and girls across age groups (Supplemental Table S2 ${ }^{1}$ ). Total sugars intake was associated with sex in young $(p=0.035)$ and older $(p=0.039)$ adolescents and immigrant status in older adolescents $(p=0.031)$, but not with either measured or self-report BMI categories (Supplemental Table $S 2^{1}$ ).

\subsection{Total, free, and added sugars intakes}

Supplemental Table $S 3^{1}$ and Fig. S2 ${ }^{1}$ present intakes of total, free, and added sugars in Canadian children and adolescents. The presentation of data is limited to Q1, Q3, and Q5 for ease of readability since the results for Q2 and Q4 did not impact the findings. In children aged 2-8 y, the mean intake of total sugars was 14.8\% $\mathrm{E}$ in $\mathrm{Q} 1,25.9 \% \mathrm{E}$ in $\mathrm{Q} 3$, and 38.1\% $\mathrm{E}$ in $\mathrm{Q} 5$, where added sugars represented $34 \%, 36 \%$, and $40 \%$ and free sugars $43 \%, 47 \%$, and $56 \%$ of total sugars in Q1, Q3, and Q5, respectively. In adolescents aged 9-13 y, the total sugars were $13.0 \% \mathrm{E}$ in Q1, 23.8\%E in Q3, and $38.0 \% \mathrm{E}$ in Q5, where added sugars represented $43 \%, 43 \%$, and $50 \%$ and free sugars $48 \%, 53 \%$, and $64 \%$ of total sugars in Q1, Q3, and Q5, respectively. In adolescents aged 14-18 $\mathrm{y}$, the total sugars were 9.2\% $\mathrm{E}$ in $\mathrm{Q} 1,21.6 \% \mathrm{E}$ in $\mathrm{Q} 3$, and $35.5 \% \mathrm{E}$ in $\mathrm{Q} 5$, where added sugars represented $45 \%, 48 \%$, and $52 \%$ and free sugars $51 \%, 57 \%$, and 63\% of total sugars in Q1, Q3 and Q5, respectively. Overall, compared with adolescents, children had a lower proportion of their total sugars coming from added sources and a higher proportion coming from naturally occurring sources.

\subsection{Food categories by sugars intake}

Among Canadian children and adolescents in Q5, consumption of fruit, confectionary, milks, and fruit juice were higher compared with Q1, and confectionary and fruit juice were higher

${ }^{1}$ Supplementary data are available with the article at https://doi.org/10.1139/apnm-2021-0517. 
Table 1. Intakes from nutrients and comparisons across quintiles of total sugars intake (\%E) in children aged 2-8 y $(n=1896)$ in Models 1 and 3.*

\begin{tabular}{|c|c|c|c|c|c|c|c|c|c|c|c|}
\hline \multirow[b]{3}{*}{ Energy (kcal) } & \multicolumn{3}{|c|}{$\mathrm{Q} 1(n=380)$} & \multicolumn{3}{|c|}{$\mathrm{Q} 3(n=379)$} & \multicolumn{3}{|c|}{$\mathrm{Q} 5(n=379)$} & \multicolumn{2}{|l|}{$p$-value ${ }^{\dagger}$} \\
\hline & \multirow{2}{*}{$\begin{array}{l}\text { Mean } \\
1676.4\end{array}$} & \multicolumn{2}{|l|}{$95 \% \mathrm{CI}$} & \multirow{2}{*}{$\begin{array}{l}\text { Mean } \\
1595.6\end{array}$} & \multicolumn{2}{|l|}{$95 \% \mathrm{CI}$} & \multirow{2}{*}{$\begin{array}{l}\text { Mean } \\
1600.6\end{array}$} & \multicolumn{2}{|l|}{$95 \% \mathrm{CI}$} & \multirow{2}{*}{$\begin{array}{c}\text { Model } 1 \\
0.247\end{array}$} & \multirow{2}{*}{$\frac{\text { Model } 3}{0.305}$} \\
\hline & & 1607.3 & 1745.5 & & 1526.0 & 1665.3 & & 1545.3 & 1655.8 & & \\
\hline Carbohydrates (\%) & $47.3^{\ddagger, \S}$ & 45.3 & 49.3 & $54.8^{\ddagger}$ & 53.6 & 56.0 & 62.8 & 61.5 & 64.1 & $<0.0001$ & $<0.0001$ \\
\hline Total sugars (\%) & $14.8^{\ddagger, \S}$ & 14.3 & 15.4 & $25.9^{\ddagger}$ & 25.6 & 26.1 & 38.2 & 37.0 & 39.3 & $<0.0001$ & $<0.0001$ \\
\hline Naturally occurring sugars (\%) & $9.7^{\ddagger, \S}$ & 9.2 & 10.3 & $16.5^{\ddagger}$ & 15.2 & 17.7 & 22.8 & 21.2 & 24.4 & $<0.0001$ & $<0.0001$ \\
\hline Added sugars (\%) & $5.1^{\ddagger, \S}$ & 4.6 & 5.6 & $9.4^{\ddagger}$ & 8.2 & 10.5 & 15.3 & 13.5 & 17.0 & $<0.0001$ & $<0.0001$ \\
\hline Saturated fat (\%) & $12.1^{\ddagger}$ & 11.3 & 12.9 & $11.2^{\ddagger}$ & 10.7 & 11.8 & 10.0 & 9.3 & 10.7 & 0.002 & 0.003 \\
\hline Monounsaturated fat (\%) & $12.8^{\ddagger, \S}$ & 12.1 & 13.6 & $10.3^{\ddagger}$ & 9.8 & 10.7 & 8.1 & 7.6 & 8.5 & $<0.0001$ & $<0.0001$ \\
\hline Polyunsaturated fat (\%) & $7.0^{\ddagger, \S}$ & 6.5 & 7.6 & $5.6^{\ddagger}$ & 5.1 & 6.1 & 4.2 & 3.9 & 4.5 & $<0.0001$ & $<0.0001$ \\
\hline Linoleic acid (\%) & $6.0^{\ddagger, \S}$ & 5.5 & 6.4 & $4.7^{\ddagger}$ & 4.3 & 5.2 & 3.5 & 3.3 & 3.8 & $<0.0001$ & $<0.0001$ \\
\hline Alpha-linolenic acid (\%) & $0.7^{\ddagger}$ & 0.7 & 0.8 & $0.6^{\ddagger}$ & 0.6 & 0.7 & 0.5 & 0.5 & 0.6 & $<0.0001$ & $<0.0001$ \\
\hline Protein (\%) & $17.6^{\ddagger, \S}$ & 16.6 & 18.6 & $15.3^{\ddagger}$ & 14.5 & 16.2 & 12.7 & 12.2 & 13.2 & $<0.0001$ & $<0.0001$ \\
\hline Thiamin (mg) & $0.9^{\ddagger}$ & 0.8 & 1.0 & 0.9 & 0.8 & 1.0 & 0.8 & 0.7 & 0.8 & 0.0001 & $<0.0001$ \\
\hline Riboflavin (mg) & $1.0^{\S}$ & 0.9 & 1.0 & 1.1 & 1.1 & 1.2 & 1.1 & 1.0 & 1.2 & $<0.0001$ & $<0.0001$ \\
\hline Niacin (mg) & $20.4^{\ddagger, \S}$ & 19.2 & 21.5 & $17.8^{\ddagger}$ & 17.1 & 18.5 & 14.3 & 13.8 & 14.9 & $<0.0001$ & $<0.0001$ \\
\hline Vitamin B-6 (mg) & 0.8 & 0.7 & 0.9 & 0.8 & 0.7 & 0.8 & 0.8 & 0.8 & 0.9 & 0.739 & 0.687 \\
\hline Folate ( $\mu \mathrm{g}$ DFE) & $259.5^{\ddagger}$ & 239.7 & 279.3 & $242.4^{\ddagger}$ & 224.0 & 260.9 & 201.9 & 188.7 & 215.2 & $<0.0001$ & $<0.0001$ \\
\hline Vitamin B-12 (mg) & 2.1 & 1.9 & 2.4 & 2.3 & 2.1 & 2.6 & 2.1 & 1.9 & 2.3 & 0.429 & 0.436 \\
\hline Vitamin C (mg) & $51.6^{\ddagger, \S}$ & 45.4 & 57.9 & $74.4^{\ddagger}$ & 66.3 & 82.5 & 112.4 & 95.3 & 129.5 & $<0.0001$ & $<0.0001$ \\
\hline Vitamin $\mathrm{D}(\mu \mathrm{g})$ & 3.4 & 2.8 & 4.0 & 4.1 & 3.6 & 4.5 & 3.7 & 3.3 & 4.0 & 0.083 & 0.079 \\
\hline Calcium (mg) & 540.1 & 502.8 & 577.4 & 624.4 & 575.3 & 673.5 & 619.6 & 572.8 & 666.4 & 0.004 & 0.003 \\
\hline Iron (mg) & 7.0 & 6.5 & 7.5 & 6.6 & 6.3 & 6.9 & 6.2 & 5.8 & 6.6 & 0.027 & 0.032 \\
\hline Magnesium (mg) & 147.9 & 137.0 & 158.8 & 151.7 & 145.0 & 158.4 & 148.6 & 143.2 & 154.0 & 0.571 & 0.573 \\
\hline Phosphorus (mg) & 743.3 & 707.6 & 779.0 & 745.9 & 706.4 & 785.3 & 697.7 & 658.3 & 737.1 & 0.203 & 0.213 \\
\hline Potassium (mg) & $1251.7^{\ddagger, \S}$ & 1184.5 & 1319.0 & 1466.0 & 1385.3 & 1546.7 & 1593.5 & 1515.7 & 1671.2 & $<0.0001$ & $<0.0001$ \\
\hline
\end{tabular}

Note: \%E, percent energy; CI, confidence interval; DFE, dietary folate equivalents; Q quintile; RAE, retinoic acid equivalent.

*Intake of nutrients across quintiles of total sugars intake (\%E) were compared using a general linear model (PROC SURVEYREG) adjusted for the following covariates: Model 1, misreporting status (determined using the methods by Garriguet (2018)); Model 3, misreporting status and sex, immigrant status and weekend reference day. Note that Quintiles 2 and 4 are not presented for readability.

${ }^{\dagger}$ The $p$-value represents the global $p$-value for a significant difference across quintiles of intake of total sugars (\%E).

${ }^{\ddagger}$ Significantly different compared with $\mathrm{Q} 5$ based on post hoc comparisons with Bonferroni correction, Model 3 ( $p<0.05$ ).

${ }^{\S}$ Significantly different compared with Q3 based on post hoc comparisons with Bonferroni correction, Model $3(p<0.05)$.

compared with Q3. Among those in Q3, milks and fruits were higher compared with Q1, with the addition of higher yogurts in children and higher fruit juice in adolescents.

In children aged 2-8 y, the mean intakes of total sugars for Q1, Q3, and Q5 were 14.8(SE 0.3)\%E, 25.9(SE 0.1)\%E, and 38.2(SE 0.6)\%E, respectively (Table 1). Children with the lowest intakes of total sugars (Q1) had lower consumption of milks, yogurts, and fruits and higher consumption of pasta, rice, cereal grains and flour, margarines and other spreads, and poultry compared with those in Q3. Additional food categories that differed when Q1 was compared with Q5 included sugars and syrups, confectionary, and fruit juice, which were lower, while intakes of cheese and eggs were higher ( $p<0.05$, Table 2$)$. Children in Q3 had lower intakes of confectionary and fruit juice and higher intakes of margarines and other spreads compared with Q5 $(p<0.05$, Table 2$)$. There were no differences for the categories of regular soft drinks, fruit drinks, breads, cookies, or cakes across quintiles.

In young adolescents aged 9-13 y, the mean intakes of total sugars for Q1, Q3, and Q5 were 13.0(SE 0.3)\%E, 23.8(SE 0.1)\%E, and 38.0 (SE 0.7)\%E, respectively (Table 3). Young adolescents with the lowest intakes of total sugars (Q1) had lower consumption of milks, fruit, fruit juice, and sugars and syrups and higher consumption of margarines and pasta, rice, cereal grains, and flour compared with those in Q3. Additional food categories, which differed when Q1 was compared with Q5, included cakes and other pastries, frozen dairy products, yogurts, confectionary, and fruit drinks, which were lower, while intakes of cheese, eggs, and poultry were higher $(p<0.05$, Table 4). Further, Q3 had lower intakes of confectionary, fruit juice, and yogurts and higher intakes of margarines and other spreads compared with Q5 ( $p<0.05$, Table 4$)$. There were no differences for the categories of regular soft drinks, breads or cookies across quintiles.

In older adolescents aged 14-18 y, the mean intakes of total sugars for Q1, Q3, and Q5 were 9.2(SE 0.6)\%E, 21.5(SE 0.2)\%E, and 35.5 (SE 0.5)\%E, respectively (Table 5). Older adolescents with the lowest intakes of total sugars (Q1) had lower consumption of milks, fruit, and fruit juice compared with those in Q3. Additional food categories that differed when Q1 was compared with Q5 included cakes and other pastries, confectionary, and soft drinks, which were lower, while intakes of pasta, rice, cereal grains and flour, cheese, eggs, margarine and other spreads, and red meat were higher $(p<0.05$, Table 6). Further, Q3 had lower intakes of confectionary and higher intakes of pasta, rice, cereal grains and flour, and other breads compared with Q5 $(p<0.05$, Table 6). 
Table 2. Intakes of food categories and comparisons across quintiles of total sugars intake (\%E) in children aged 2-8 y $(n=1896)$ in Models 1 and 2.*

\begin{tabular}{|c|c|c|c|c|c|c|c|c|c|c|c|}
\hline \multirow{3}{*}{$\begin{array}{l}\text { Food category } \\
\text { Pasta, rice, cereal grains, and flour }\end{array}$} & \multicolumn{3}{|c|}{$\mathrm{Q} 1(n=380)$} & \multicolumn{3}{|c|}{$\mathrm{Q} 3(n=379)$} & \multicolumn{3}{|c|}{$\mathrm{Q} 5(n=379)$} & \multicolumn{2}{|l|}{$p$-value ${ }^{\dagger}$} \\
\hline & \multirow{2}{*}{$\begin{array}{l}\text { Mean } \\
120.8^{\ddagger, \S}\end{array}$} & \multicolumn{2}{|l|}{$95 \%$ CI } & \multirow{2}{*}{$\begin{array}{c}\text { Mean } \\
73.7\end{array}$} & \multicolumn{2}{|l|}{$95 \% \mathrm{CI}$} & \multirow{2}{*}{$\begin{array}{c}\text { Mean } \\
58.1\end{array}$} & \multicolumn{2}{|l|}{$95 \% \mathrm{CI}$} & \multirow{2}{*}{ 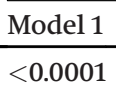 } & \multirow{2}{*}{$\frac{\text { Model 2 }}{<0.0001}$} \\
\hline & & 97.3 & 144.4 & & 57.8 & 89.6 & & 44.5 & 71.6 & & \\
\hline White breads & 22.7 & 15.7 & 29.8 & 27.8 & 11.2 & 44.4 & 15.7 & 9.9 & 21.6 & 0.325 & 0.422 \\
\hline Other breads & 35.4 & 25.4 & 45.4 & 30.5 & 20.9 & 40.1 & 23.0 & 18.8 & 27.2 & 0.001 & 0.004 \\
\hline Wholegrain and high fibre breakfast cereals & 14.5 & -5.3 & 34.4 & 11.2 & 6.9 & 15.5 & 10.3 & 1.6 & 19.0 & 0.651 & 0.668 \\
\hline Other breakfast cereals & 5.7 & 3.2 & 8.1 & 6.9 & 4.3 & 9.5 & 8.6 & 5.8 & 11.4 & 0.270 & 0.271 \\
\hline Frozen dairy products & 9.3 & 2.0 & 16.5 & 11.0 & 4.7 & 17.4 & 18.2 & 9.8 & 26.5 & 0.021 & 0.010 \\
\hline Milks & $239.0^{\ddagger, \S}$ & 203.6 & 274.5 & 381.9 & 322.6 & 441.3 & 365.0 & 313.8 & 416.2 & $<0.0001$ & $<0.0001$ \\
\hline Creams & 2.3 & 0.0 & 4.6 & 2.9 & 0.3 & 5.5 & 0.7 & 0.1 & 1.3 & 0.094 & 0.115 \\
\hline Cheeses & $37.0^{\ddagger}$ & 28.2 & 45.8 & 23.9 & 18.9 & 29.0 & 17.1 & 13.5 & 20.7 & 0.000 & 0.001 \\
\hline Yogurts (natural and with fruits) & $25.5^{\S}$ & 14.7 & 36.3 & 52.1 & 40.1 & 64.1 & 72.7 & 45.4 & 100.0 & 0.001 & 0.001 \\
\hline Eggs & $16.5^{\ddagger}$ & 12.2 & 20.7 & 12.8 & 9.1 & 16.5 & 7.1 & 4.2 & 9.9 & 0.000 & $<0.0001$ \\
\hline Poultry & $46.1^{\ddagger, \S}$ & 31.7 & 60.5 & 18.0 & 9.3 & 26.8 & 15.0 & 10.5 & 19.4 & $<0.0001$ & $<0.0001$ \\
\hline Nuts, seeds, peanut butter & 8.6 & 3.5 & 13.6 & 5.1 & 2.1 & 8.2 & 3.9 & 2.5 & 5.2 & 0.302 & 0.308 \\
\hline Fish, shellfish & 19.5 & 6.4 & 32.6 & 8.5 & 2.8 & 14.1 & 4.4 & 1.7 & 7.0 & 0.079 & 0.079 \\
\hline Vegetables & 105.6 & 83.7 & 127.5 & 114.0 & 90.3 & 137.6 & 80.8 & 58.7 & 102.9 & 0.112 & 0.162 \\
\hline Legumes & 18.5 & 7.0 & 29.9 & 4.5 & 2.2 & 6.7 & 5.6 & 1.6 & 9.6 & 0.169 & 0.204 \\
\hline Potatoes, fried & 12.2 & 6.5 & 17.8 & 5.2 & 3.1 & 7.3 & 6.0 & 3.5 & 8.5 & 0.022 & 0.049 \\
\hline Potatoes, raw and cooked & 12.0 & 5.5 & 18.5 & 16.0 & 8.2 & 23.7 & 18.3 & 10.4 & 26.3 & 0.808 & 0.772 \\
\hline Fruit & $99.0^{\ddagger, \S}$ & 81.7 & 116.4 & 201.2 & 170.9 & 231.5 & 254.4 & 222.5 & 286.3 & $<0.0001$ & $<0.0001$ \\
\hline Sugars, syrups, preserves & $5.8^{\ddagger}$ & 2.7 & 8.8 & 11.0 & 6.5 & 15.5 & 19.3 & 13.5 & 25.1 & $<0.0001$ & $<0.0001$ \\
\hline Savory snacks & 6.6 & 2.3 & 11.0 & 4.2 & 2.0 & 6.4 & 3.8 & 2.1 & 5.5 & 0.195 & 0.276 \\
\hline Confectionary & $9.6^{\ddagger}$ & 5.6 & 13.6 & $19.2^{\ddagger}$ & 10.6 & 27.8 & 54.5 & 36.6 & 72.4 & $<0.0001$ & $<0.0001$ \\
\hline Fruit juice & $84.6^{\ddagger}$ & 56.9 & 112.3 & $117.2^{\ddagger}$ & 93.4 & 140.9 & 211.2 & 165.0 & 257.4 & $<0.0001$ & $<0.0001$ \\
\hline Condiments, gravies & 15.7 & 10.3 & 21.1 & 11.9 & 4.9 & 19.0 & 14.7 & 7.2 & 22.2 & 0.275 & 0.315 \\
\hline
\end{tabular}

Note: \%E, percent energy; CI, confidence interval; Q quintile.

*Mean intakes (grams/day) of food categories across quintiles of total sugars intake (\%E) were compared using a general linear model (PROC SURVEYREG) adjusted

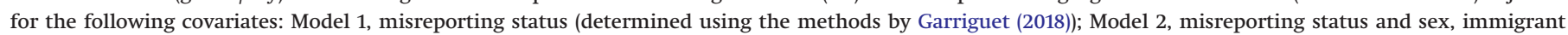
status, weekend reference day and total energy intake. Food categories are aligned with those presented in the 2015 Canadian Community Health Survey (CCHS)-

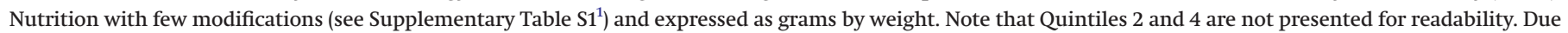
to a large number of non-consumption owing to single-day dietary recall data, the lower bounds of the $95 \%$ CIs for a few food categories were below zero.

${ }^{\dagger}$ The $p$-value represents the global $p$-value for a significant difference across quintiles of intake of total sugars (\%E).

${ }^{\ddagger}$ Significantly different compared with Q5 based on post hoc comparisons with Bonferroni correction, Model 2 ( $\left.p<0.05\right)$.

${ }^{\S}$ Significantly different compared with Q3 based on post hoc comparisons with Bonferroni correction, Model $2(p<0.05)$.

\subsection{Top food categories contributing to sugars intake}

To better understand the food categories that contributed to the increase in total sugars intakes across quintiles, we calculated the \%E coming from sugars in each food category within each quintile. Overall, the higher intake of total sugars in Q3 compared with Q1 can primarily be explained by more sugars coming from fruit, milks, and fruit juice across all age groups with the addition of frozen dairy products and fruit drinks in young adolescents and soft drinks in older adolescents. The higher sugars intake in Q5 compared with Q3 can primarily be explained by fruit juice, fruit drinks, fruit, confectionary, and sugars and syrups, with the addition of cakes and pastries in young adolescents and soft drinks in older adolescents.

In children aged 2-8 y, total sugars in Q3 was $~ 11 \% \mathrm{E}$ higher than Q1 due to fruit intake (increased contribution to total sugars by $+2.7 \% \mathrm{E})$, milks $(+2.1 \% \mathrm{E})$, fruit juice $(+1.2 \% \mathrm{E})$, yogurts $(+0.9 \% \mathrm{E})$, and confectionary $(+0.9 \% \mathrm{E})$ (Supplemental Tables $\left.\mathrm{S} 4-\mathrm{S} 5^{1}\right)$. There was a $12 \% \mathrm{E}$ higher total sugars intake in Q5 compared with Q3 due to increased intakes of fruit juice $(+3.1 \% \mathrm{E})$, fruit $(+2.5 \% \mathrm{E})$, confectionary $(+2.4 \% \mathrm{E})$, sugars and syrups $(+1.0 \% \mathrm{E})$, and fruit drinks (+0.9\%E).

In young adolescents aged 9-13 y, total sugars in Q3 was $11 \% \mathrm{E}$ higher compared with Q1 due to increased intakes of fruit $(+2.7 \% \mathrm{E})$, fruit juice $(+1.5 \% \mathrm{E})$, frozen dairy products $(+1.3 \% \mathrm{E})$, fruit drinks $(+1.2 \% \mathrm{E})$, and milks $(+1.1 \% \mathrm{E})$ (Supplemental Tables S6-S7 $\left.{ }^{1}\right)$. There was a $\sim 14 \% \mathrm{E}$ higher total sugars intake in Q5 compared with Q3, due to increased confectionary $(+4.7 \% \mathrm{E})$, fruit juice $(+2.5 \% \mathrm{E})$, fruit $(+1.9 \% \mathrm{E})$, cakes and other pastries $(+1.4 \% \mathrm{E})$, and fruit drinks $(+1.1 \% \mathrm{E})$.

In older adolescents aged 14-18 y, total sugars in Q3 was $\sim 12 \% \mathrm{E}$ higher compared with Q1 due to increased intakes of fruit $(+2.1 \% \mathrm{E})$, milks $(+1.7 \% \mathrm{E})$, soft drinks $(+1.6 \% \mathrm{E})$, fruit juice $(+1.4 \% \mathrm{E})$, and sugars and syrups (+0.9\%E) (Supplemental Tables S8-S9 $\left.{ }^{1}\right)$. There was a $14 \% \mathrm{E}$ 
Table 3. Intakes from nutrients and comparisons across quintiles of total sugars intake (\%E) in young adolescents aged 9-13 y $(n=1842)$ in Models 1 and $3 .^{*}$

\begin{tabular}{|c|c|c|c|c|c|c|c|c|c|c|c|}
\hline \multirow[b]{3}{*}{ Energy (kcal) } & \multicolumn{3}{|c|}{$\mathrm{Q} 1(n=369)$} & \multicolumn{3}{|c|}{$\mathrm{Q} 3(n=368)$} & \multicolumn{3}{|c|}{$\mathrm{Q} 5(n=369)$} & \multicolumn{2}{|l|}{$p$-value ${ }^{\dagger}$} \\
\hline & \multirow{2}{*}{$\begin{array}{l}\text { Mean } \\
1987.7\end{array}$} & \multicolumn{2}{|l|}{$95 \% \mathrm{CI}$} & \multirow{2}{*}{$\begin{array}{l}\text { Mean } \\
1972.5\end{array}$} & \multicolumn{2}{|l|}{$95 \% \mathrm{CI}$} & \multirow{2}{*}{$\begin{array}{l}\text { Mean } \\
1969.4\end{array}$} & \multicolumn{2}{|l|}{$95 \%$ CI } & \multirow{2}{*}{$\begin{array}{c}\text { Model1 } \\
0.970\end{array}$} & \multirow{2}{*}{$\frac{\text { Model } 3}{0.992}$} \\
\hline & & 1898.2 & 2077.2 & & 1900.8 & 2044.3 & & 1899.1 & 2039.8 & & \\
\hline Carbohydrates (\%) & $47.1^{\ddagger, \S}$ & 45.8 & 48.3 & $54.5^{\ddagger}$ & 52.4 & 56.7 & 62.7 & 61.2 & 64.1 & $<0.0001$ & $<0.0001$ \\
\hline Total sugars (\%) & $13.0^{\ddagger, \S}$ & 12.5 & 13.5 & $23.8^{\ddagger}$ & 23.5 & 24.0 & 38.0 & 36.7 & 39.3 & $<0.0001$ & $<0.0001$ \\
\hline Naturally occurring sugars (\%) & $7.4^{\ddagger, \S}$ & 6.6 & 8.1 & $13.5^{\ddagger}$ & 12.7 & 14.3 & 18.7 & 16.7 & 20.8 & $<0.0001$ & $<0.0001$ \\
\hline Added sugars (\%) & $5.6^{\ddagger, \S}$ & 4.8 & 6.5 & $10.2^{\ddagger}$ & 9.4 & 11.0 & 19.3 & 17.0 & 21.5 & $<0.0001$ & $<0.0001$ \\
\hline Saturated fat (\%) & $11.9^{\ddagger}$ & 11.2 & 12.5 & 11.3 & 10.5 & 12.0 & 9.8 & 9.0 & 10.6 & $<0.0001$ & $<0.0001$ \\
\hline Monounsaturated fat (\%) & $13.5^{\ddagger, \S}$ & 12.7 & 14.3 & $10.6^{\ddagger}$ & 9.5 & 11.7 & 8.4 & 7.9 & 8.8 & $<0.0001$ & $<0.0001$ \\
\hline Polyunsaturated fat (\%) & $7.1^{\ddagger, \S}$ & 6.7 & 7.4 & $5.8^{\ddagger}$ & 5.3 & 6.3 & 4.5 & 4.2 & 4.8 & $<0.0001$ & $<0.0001$ \\
\hline Linoleic acid (\%) & $6.1^{\ddagger, \S}$ & 5.8 & 6.4 & $4.9^{\ddagger}$ & 4.4 & 5.4 & 3.8 & 3.6 & 4.1 & $<0.0001$ & $<0.0001$ \\
\hline Alpha-linolenic acid (\%) & $0.8^{\ddagger}$ & 0.7 & 0.9 & $0.6^{\ddagger}$ & 0.6 & 0.7 & 0.5 & 0.5 & 0.6 & $<0.0001$ & $<0.0001$ \\
\hline Protein (\%) & $17.3^{\ddagger, \S}$ & 16.2 & 18.4 & $14.9^{\ddagger}$ & 14.3 & 15.6 & 12.2 & 11.6 & 12.9 & $<0.0001$ & $<0.0001$ \\
\hline Thiamin (mg) & 1.0 & 0.9 & 1.0 & 0.9 & 0.8 & 1.0 & 0.8 & 0.7 & 0.9 & 0.088 & 0.050 \\
\hline Riboflavin (mg) & 1.0 & 0.9 & 1.0 & 1.1 & 0.9 & 1.2 & 0.9 & 0.9 & 1.0 & 0.210 & 0.185 \\
\hline Niacin (mg) & $20.6^{\ddagger, \S}$ & 19.1 & 22.1 & $17.7^{\ddagger}$ & 16.9 & 18.6 & 14.1 & 13.2 & 15.1 & $<0.0001$ & $<0.0001$ \\
\hline Vitamin B-6 (mg) & 0.8 & 0.7 & 0.9 & 0.8 & 0.7 & 0.8 & 0.7 & 0.6 & 0.7 & 0.201 & 0.202 \\
\hline Folate ( $\mu \mathrm{g}$ DFE) & $262.8^{\ddagger}$ & 241.2 & 284.4 & $241.4^{\ddagger}$ & 220.5 & 262.2 & 194.0 & 178.6 & 209.5 & $<0.0001$ & $<0.0001$ \\
\hline Vitamin B-12 (mg) & 2.1 & 1.9 & 2.3 & 3.1 & 1.0 & 5.2 & 1.9 & 1.7 & 2.0 & 0.162 & 0.160 \\
\hline Vitamin C (mg) & $39.7^{\ddagger, \S}$ & 28.2 & 51.1 & $58.6^{\ddagger}$ & 50.4 & 66.7 & 91.2 & 72.6 & 109.7 & $<0.0001$ & $<0.0001$ \\
\hline Vitamin $\mathrm{D}(\mu \mathrm{g})$ & 2.7 & 2.2 & 3.3 & 2.9 & 2.6 & 3.2 & 2.9 & 2.6 & 3.3 & 0.607 & 0.654 \\
\hline Calcium (mg) & 468.4 & 419.7 & 517.0 & 514.8 & 479.2 & 550.4 & 521.4 & 482.1 & 560.8 & 0.437 & 0.485 \\
\hline Iron (mg) & 7.0 & 6.6 & 7.5 & $7.1^{\ddagger}$ & 6.6 & 7.5 & 6.4 & 5.7 & 7.0 & 0.007 & 0.007 \\
\hline Magnesium (mg) & 132.3 & 123.8 & 140.8 & 140.5 & 134.8 & 146.3 & 131.0 & 125.0 & 136.9 & 0.117 & 0.097 \\
\hline Phosphorus (mg) & 685.9 & 638.7 & 733.2 & $684.8^{\ddagger}$ & 658.1 & 711.5 & 625.2 & 594.2 & 656.3 & 0.020 & 0.013 \\
\hline Potassium (mg) & 1201.3 & 1109.7 & 1292.8 & 1300.8 & 1233.5 & 1368.0 & 1369.0 & 1293.6 & 1444.5 & 0.014 & 0.024 \\
\hline
\end{tabular}

Note: \%E, percent energy; CI, confidence interval; DFE, dietary folate equivalents; Q quintile; RAE, retinoic acid equivalent.

*Intake of nutrients across quintiles of total sugars intake (\%E) were compared using a general linear model (PROC SURVEYREG) adjusted for the following covariates: Model 1, misreporting status (determined using the methods by Garriguet (2018)); Model 3, misreporting status and sex, immigrant status and weekend reference day. Note that Quintiles 2 and 4 are not presented for readability.

${ }^{\dagger}$ The $p$-value represents the global $p$-value for a significant difference across quintiles of intake of total sugars (\%E).

${ }^{\ddagger}$ Significantly different compared with Q5 based on post hoc comparisons with Bonferroni correction, Model 3 ( $p<0.05$ ).

${ }^{\S}$ Significantly different compared with Q3 based on post hoc comparisons with Bonferroni correction, Model 3 ( $p<0.05$ ).

higher total sugars intake in Q5 compared with Q3, due to increased fruit $(+2.7 \% \mathrm{E})$, confectionary $(+2.3 \% \mathrm{E})$, soft drinks $(+2.0 \% \mathrm{E})$, fruit juice $(+1.6 \% \mathrm{E})$, fruit drinks $(+1.1 \% \mathrm{E})$, milks $(+1.0 \% \mathrm{E})$, and sugars and syrups $(+1.0 \% \mathrm{E})$.

\subsection{Macronutrients and micronutrients by sugars intake}

Canadian children and adolescents had no differences in energy intake across quintiles of total sugars intakes. Those with lower intakes of total sugars (Q1) and those representing the approximate mean level of intake (Q3) generally ( $\geq 2$ age groups) had lower \%E from carbohydrates, total, natural, added, and free sugars, and higher protein, fat (including subcategories of fat), thiamin, niacin, folate, zinc, and sodium compared with those with higher intakes of total sugars (Q5). Further, those in Q1 generally had lower vitamin $C$ and potassium, and higher niacin compared with those with higher intakes of total sugars ( $Q 3$ or $Q 5)$. In children aged 2-8 y, Q3 had higher vitamin C, potassium, and riboflavin compared with $\mathrm{Q} 1$, and in adolescents aged 14-18 y, Q3 had higher fibre, vitamin C, and calcium compared with Q1, while adolescents aged 9-13 y in Q3 had higher phosphorus and iron compared with Q5.
Table 1 and Supplemental Figs. S3-S8 ${ }^{1}$ present the nutrient results for children aged 2-8 y. In children, total sugars accounted for $31 \%, 47 \%$, and $61 \%$ of total carbohydrate intake in Q1, Q3, and Q5, respectively. Compared with Q5, Q1 and Q3 were both higher in protein, MUFA, PUFA, linoleic acid, alpha-linolenic acid, saturated fat, and cholesterol $(p<0.05)$. With regards to micronutrients, Q1 and Q3 were both higher in niacin, folate, zinc, and sodium and lower in vitamin C compared with Q5 $(p<0.05)$. Q1 was also higher in thiamin and lower in potassium compared with Q5 $(p<0.05)$. Compared with Q3, Q1 had higher protein, MUFA, PUFA, and linoleic acid. Q3 and Q1 differed in only 4/16 micronutrients; while Q1 had higher niacin, Q3 had higher vitamin C, potassium, and riboflavin $(p<0.05)$. Dietary fibre intakes did not differ significantly across quintiles.

Table 3 and Supplemental Figs. S3-S8 ${ }^{1}$ present the nutrient intakes for adolescents aged 9-13 y. In young adolescents, total sugars accounted for $28 \%, 44 \%$, and $61 \%$ of total carbohydrates in Q1, Q3, and Q5, respectively. Compared with Q5, both Q1 and Q3 had higher protein, MUFA, PUFA, linoleic acid, alpha-linolenic acid, niacin, folate, zinc, and sodium and lower vitamin $C$, while Q1 also had higher saturated fat and Q3 also had higher iron and 
Table 4. Intakes of food categories and comparisons across quintiles of total sugars intake (\%E) in young adolescents aged 9-13 y $(n=1842)$ in Models 1 and $2 .^{*}$

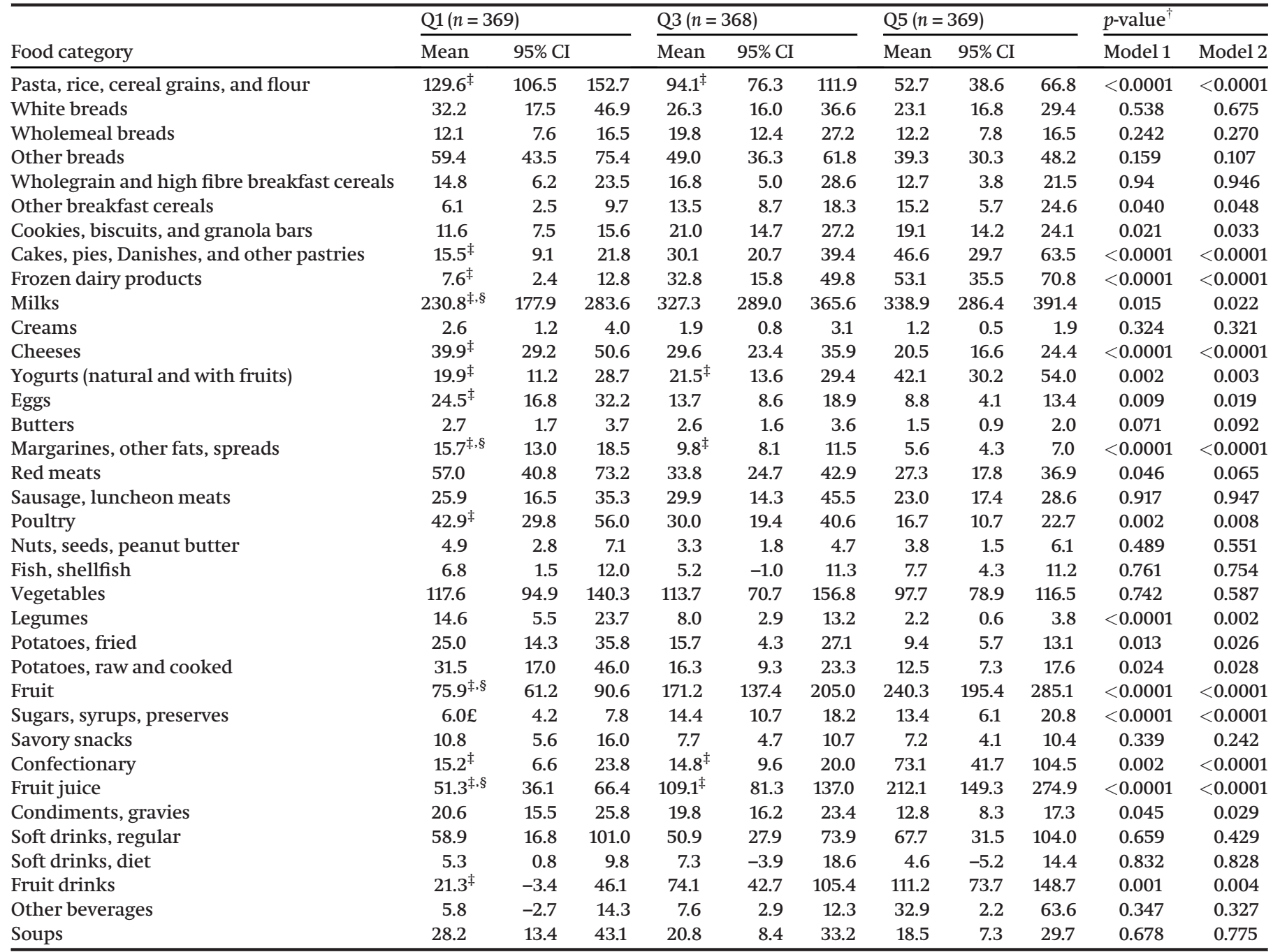

Note: \%E, percent energy; CI, confidence interval; Q quintile.

${ }^{*}$ Mean intakes (grams/day) of food categories across quintiles of total sugars intake (\%E) were compared using a general linear model (PROC SURVEYREG) adjusted for the following covariates: Model 1, misreporting status (determined using the methods by Garriguet (2018)); Model 2, misreporting status and sex, immigrant status, weekend reference day and total energy intake. Food categories are aligned with those presented in the 2015 Canadian Community Health Survey (CCHS)Nutrition with few modifications (see Supplementary Table S1 $1^{1}$ ) and expressed as grams by weight. Note: Quintiles 2 and 4 are not presented for readability. Due to a large number of non-consumption owing to single-day dietary recall data, the lower bounds of the $95 \%$ CIs for a few food categories were below zero.

${ }^{\dagger}$ The $p$-value represents the global $p$-value for a significant difference across quintiles of intake of total sugars (\%E).

${ }^{\ddagger}$ Significantly different compared with Q5 based on post hoc comparisons with Bonferroni correction, Model $2(p<0.05)$.

§Significantly different compared with Q3 based on post hoc comparisons with Bonferroni correction, Model $2(p<0.05)$.

phosphorus $(p<0.05)$. Compared with Q3, Q1 had higher protein, MUFA, PUFA, linoleic acid $(p<0.05)$. Q3 and Q1 did not differ for 14/16 micronutrients; while Q1 had higher niacin, and Q3 had higher vitamin $C(p<0.05)$. Dietary fibre intakes did not differ significantly across quintiles.

Table 5 and Supplemental Figs. S3-S8 ${ }^{1}$ present the nutrient intakes for adolescents aged 14-18 y. In older adolescents, total sugars accounted for $22 \%, 40 \%$, and $59 \%$ of total carbohydrates in Q1, Q3, and Q5, respectively. Compared with Q5, Q1 and Q3 had higher protein, MUFA, cholesterol, niacin, and zinc, while Q1 also had higher linoleic acid and alpha-linolenic acid and lower vitamin C, potassium, and calcium, and Q3 had higher thiamin $(p<0.05)$. Compared with Q3, Q1 had higher protein, MUFA, PUFA, linoleic acid, alpha-linolenic acid, niacin, and sodium, while Q3 had higher fibre, vitamin $\mathrm{C}$, and calcium $(p<0.05)$.

\section{Discussion}

\subsection{The consumption of sugars among Canadian children and adolescents}

Overall, when stratified into quintiles by total sugars intake, Canadian children and adolescents consumed 9.2-14.8\%E in Q1, 21.6-25.9\% $\mathrm{E}$ in $\mathrm{Q} 3$, and $35.5-38.1 \% \mathrm{E}$ in $\mathrm{Q} 5$ as total sugars, where 4.1-5.1\%E, 9.3-10.3\%E, and 15.3-19.2\%E were consumed as added sugars and $4.7-6.4 \% \mathrm{E}, 10.3-12.1 \% \mathrm{E}$, and $21.3-24.4 \% \mathrm{E}$ came from free sugars, respectively. Added sugars intakes in Q3, representing the mean, were close to the $10 \% \mathrm{E}$ recommendation in the US dietary guidelines (United States Department of Agriculture and United States Department of Health and Human Services 2016), whereas the free sugars intakes were higher than the WHO recommendation of limiting free sugars to $<10 \% \mathrm{E}$ (WHO 2015). According to a review of global sugars intakes, the sugars intakes 
Table 5. Intakes from nutrients and comparisons across quintiles of total sugars intake (\%E) in older adolescents aged 14-18 y $(n=1753)$ in Models 1 and $3 .^{*}$

\begin{tabular}{|c|c|c|c|c|c|c|c|c|c|c|c|}
\hline \multirow[b]{3}{*}{ Energy (kcal) } & \multicolumn{3}{|c|}{$\mathrm{Q} 1(n=351)$} & \multicolumn{3}{|c|}{$\mathrm{Q} 3(n=351)$} & \multicolumn{3}{|c|}{$\mathrm{Q} 5(n=351)$} & \multicolumn{2}{|l|}{$p$-value ${ }^{\dagger}$} \\
\hline & \multirow{2}{*}{$\begin{array}{l}\text { Mean } \\
2146.4\end{array}$} & \multicolumn{2}{|l|}{$95 \% \mathrm{CI}$} & \multirow{2}{*}{$\begin{array}{l}\text { Mean } \\
2080.9\end{array}$} & \multicolumn{2}{|l|}{$95 \% \mathrm{CI}$} & \multirow{2}{*}{$\begin{array}{l}\text { Mean } \\
2013.7\end{array}$} & \multicolumn{2}{|l|}{$95 \% \mathrm{CI}$} & \multirow{2}{*}{$\begin{array}{c}\text { Model 1 } \\
0.107\end{array}$} & \multirow{2}{*}{$\frac{\text { Model } 3}{0.118}$} \\
\hline & & 2030.9 & 2261.9 & & 1955.7 & 2206.0 & & 1902.9 & 2124.5 & & \\
\hline Carbohydrates (\%) & $42.0^{\ddagger, \S}$ & 38.8 & 45.2 & $53.4^{\ddagger}$ & 51.6 & 55.2 & 59.7 & 57.9 & 61.6 & $<0.0001$ & $<0.0001$ \\
\hline Total sugars (\%) & $9.2^{\ddagger, \S}$ & 8.1 & 10.4 & $21.5^{\ddagger}$ & 21.2 & 21.9 & 35.5 & 34.6 & 36.4 & $<0.0001$ & $<0.0001$ \\
\hline Naturally occurring sugars (\%) & $5.1^{\ddagger, \S}$ & 4.1 & 6.2 & $11.2^{\ddagger}$ & 10.4 & 12.1 & 16.8 & 15.2 & 18.5 & $<0.0001$ & $<0.0001$ \\
\hline Added sugars (\%) & $4.1^{\ddagger, \S}$ & 3.6 & 4.6 & $10.3^{\ddagger}$ & 9.3 & 11.2 & 18.6 & 16.8 & 20.4 & $<0.0001$ & $<0.0001$ \\
\hline Saturated fat (\%) & 11.7 & 10.8 & 12.6 & 10.7 & 10.1 & 11.3 & 10.1 & 8.7 & 11.6 & 0.231 & 0.199 \\
\hline Monounsaturated fat (\%) & $14.9^{\ddagger, \S}$ & 13.6 & 16.1 & $11.1^{\ddagger}$ & 10.2 & 11.9 & 9.0 & 8.3 & 9.7 & $<0.0001$ & $<0.0001$ \\
\hline Polyunsaturated fat (\%) & $7.9^{\ddagger, \S}$ & 7.4 & 8.4 & 6.0 & 5.4 & 6.6 & 5.1 & 4.7 & 5.6 & $<0.0001$ & $<0.0001$ \\
\hline Linoleic acid (\%) & $6.6^{\ddagger, \S}$ & 6.2 & 7.1 & 5.2 & 4.7 & 5.7 & 4.3 & 3.9 & 4.7 & $<0.0001$ & $<0.0001$ \\
\hline Alpha-linolenic acid (\%) & $0.8^{\ddagger, \S}$ & 0.7 & 0.9 & 0.6 & 0.5 & 0.7 & 0.6 & 0.5 & 0.6 & $<0.0001$ & $<0.0001$ \\
\hline Protein (\%) & $19.9^{\ddagger, \S}$ & 17.5 & 22.2 & $15.8^{\ddagger}$ & 15.0 & 16.5 & 13.4 & 12.5 & 14.3 & $<0.0001$ & $<0.0001$ \\
\hline Thiamin (mg) & 0.9 & 0.8 & 0.9 & $0.9^{\ddagger}$ & 0.8 & 1.0 & 0.8 & 0.7 & 0.9 & $<0.0001$ & $<0.0001$ \\
\hline Riboflavin (mg) & 0.9 & 0.8 & 1.0 & 1.0 & 0.9 & 1.0 & 0.9 & 0.9 & 1.0 & 0.177 & 0.228 \\
\hline Niacin (mg) & $25.1^{\ddagger, \S}$ & 22.1 & 28.2 & $19.6^{\ddagger}$ & 18.6 & 20.7 & 16.5 & 15.0 & 18.0 & $<0.0001$ & $<0.0001$ \\
\hline Vitamin B-6 (mg) & 1.0 & 0.8 & 1.2 & 0.8 & 0.7 & 0.9 & 0.8 & 0.7 & 0.9 & 0.130 & 0.096 \\
\hline Folate ( $\mu \mathrm{g}$ DFE) & 234.4 & 204.8 & 264.0 & $246.3^{\ddagger}$ & 227.8 & 264.9 & 194.2 & 179.6 & 208.8 & $<0.0001$ & $<0.0001$ \\
\hline Vitamin B-12 (mg) & 2.7 & 1.9 & 3.6 & 2.0 & 1.7 & 2.2 & 1.9 & 1.7 & 2.2 & 0.834 & 0.872 \\
\hline Vitamin C (mg) & $31.5^{\ddagger, \S}$ & 26.2 & 36.7 & 65.3 & 56.2 & 74.4 & 80.2 & 68.7 & 91.6 & $<0.0001$ & $<0.0001$ \\
\hline Vitamin $\mathrm{D}(\mu \mathrm{g})$ & 2.8 & 2.2 & 3.3 & 2.7 & 2.2 & 3.2 & 3.2 & 2.3 & 4.1 & 0.646 & 0.617 \\
\hline Calcium (mg) & $374.4^{\ddagger, \S}$ & 335.7 & 413.2 & 462.7 & 429.8 & 495.7 & 501.6 & 459.4 & 543.8 & $<0.0001$ & $<0.0001$ \\
\hline Iron (mg) & 6.6 & 6.3 & 7.0 & 6.7 & 6.4 & 7.0 & 6.1 & 5.7 & 6.5 & 0.021 & 0.023 \\
\hline Magnesium (mg) & 138.6 & 129.9 & 147.4 & 143.8 & 136.1 & 151.5 & 149.2 & 137.7 & 160.6 & 0.168 & 0.153 \\
\hline Phosphorus (mg) & 701.8 & 656.0 & 747.6 & 662.5 & 634.1 & 690.9 & 671.1 & 611.3 & 731.0 & 0.160 & 0.145 \\
\hline Potassium (mg) & $1154.2^{\ddagger}$ & 1069.0 & 1239.5 & 1271.1 & 1195.7 & 1346.5 & 1441.5 & 1346.6 & 1536.4 & $<0.0001$ & $<0.0001$ \\
\hline
\end{tabular}

Note: \%E, percent energy; CI, confidence interval; DFE, dietary folate equivalents; Q quintile; RAE, retinoic acid equivalent.

*Intake of nutrients across quintiles of total sugars intake (\%E) were compared using a general linear model (PROC SURVEYREG) adjusted for the following covariates: Model 1, misreporting status (determined using the methods by Garriguet (2018)); Model 3, misreporting status and sex, immigrant status and weekend reference day. Note that Quintiles 2 and 4 are not presented for readability.

The $p$-value represents the global $p$-value for a significant difference across quintiles of intake of total sugars (\%E).

${ }^{\ddagger}$ Significantly different compared with Q5 based on post hoc comparisons with Bonferroni correction, Model 3 ( $p<0.05$ ).

${ }^{\S}$ Significantly different compared with Q3 based on post hoc comparisons with Bonferroni correction, Model 3 ( $\left.p<0.05\right)$.

of Canadian children and adolescents are similar to or below those in most other developed countries where data are available (Newens and Walton 2016). The added sugars intake is similar to that in Australian children ( 11\%E, Australian Health Survey 2011-2013) (Brand-Miller and Barclay 2017), but slightly lower than in the US (12\%E in 2-8 y, 14\%E in 9-18 y, NHANES 2009-2014) (Fulgoni et al. 2019). Reviews of sugars intakes in children across European countries show broad differences ranging from 16-26\%E from total and 11-17\%E from added sugars (Azais-Braesco et al. 2017). Generally, Canadian children and adolescents have lower sugars intakes compared with most European countries (Della Corte et al. 2020). For example, in Germany, intakes averaged $24-28 \% \mathrm{E}$ from total and 12-13\%E from added sugars between 2006-2016 (Perrar et al. 2020). Further, a large European cohort study conducted between 2007-2008 of nearly 10000 children aged 2-9 y from Belgium, Cyprus, Estonia, Germany, Hungary, Italy, Spain, and Sweden, found that total sugars intakes were $>20 \% \mathrm{E}$ in each country with the exception of Estonia (19\%E) (Svensson et al. 2014). However, Canadians have similar or higher total sugars intakes compared with Ireland (19\%E total sugars in 5-12 y) (Irish Universities
Nutrition Alliance 2020) and Spain (18.7\%E and 17.7\%E total sugars in 9-12 y and 13-17 y, respectively) (Ruiz et al. 2016). Relative to Canadian adults who consume $18.8 \% \mathrm{E}$ as total sugars $(8.6 \% \mathrm{E}$ added sugars), Canadian children and adolescents have higher intakes of total sugars (22-26\%E); however, a greater proportion of this comes from naturally occurring sugars. Higher total and added sugars intakes in children and adolescents compared with adults have been observed in other countries (Azais-Braesco et al. 2017; Newens and Walton 2016).

\subsection{Energy and nutrient intakes among Canadian children and adolescents}

No differences in energy intakes across quintiles of total sugars intakes were observed among children or adolescents, nor between BMI and total sugars. Sugars are commonly highlighted as a public health concern in that excess energy intake from free sugars can lead to tooth decay and excess calorie consumption (Health Canada 2018; WHO 2015). However, the present data do not seem to support that higher sugars intakes are associated with greater caloric intake in Canadian children and adolescents. 
Table 6. Intake of food categories and comparisons across quintiles of total sugars intake (\%E) in older adolescents aged $14-18 \mathrm{y}(n=1753)$ in Models 1 and 2.*

\begin{tabular}{|c|c|c|c|c|c|c|c|c|c|c|c|}
\hline \multirow{3}{*}{$\begin{array}{l}\text { Food category } \\
\text { Pasta, rice, cereal grains, and flour }\end{array}$} & \multicolumn{3}{|c|}{ Q1 $(n=351)$} & \multicolumn{3}{|c|}{$\mathrm{Q} 3(n=351)$} & \multicolumn{3}{|c|}{ Q5 $(n=351)$} & \multicolumn{2}{|l|}{$p$-value ${ }^{\dagger}$} \\
\hline & \multirow{2}{*}{$\frac{\text { Mean }}{168.7^{\ddagger}}$} & \multicolumn{2}{|l|}{$95 \% \mathrm{CI}$} & \multirow{2}{*}{$\frac{\text { Mean }}{137.9^{\ddagger}}$} & \multicolumn{2}{|l|}{$95 \% \mathrm{CI}$} & \multirow{2}{*}{$\begin{array}{r}\text { Mean } \\
66.9\end{array}$} & \multicolumn{2}{|l|}{$95 \% \mathrm{CI}$} & \multirow{2}{*}{$\frac{\text { Model } 1}{<0.0001}$} & \multirow{2}{*}{$\frac{\text { Model } 2}{<0.0001}$} \\
\hline & & 137.2 & 200.3 & & 103.4 & 172.4 & & 54.4 & 79.5 & & \\
\hline White breads & 25.3 & 14.7 & 35.8 & 26.2 & 18.4 & 34.1 & 19.5 & 13.4 & 25.7 & 0.691 & 0.917 \\
\hline Other breads & 45.6 & 28.2 & 63.0 & $54.7^{\ddagger}$ & 38.6 & 70.7 & 27.6 & 19.9 & 35.2 & $<0.0001$ & $<0.0001$ \\
\hline Wholegrain and high fibre breakfast cereals & 8.8 & 4.8 & 12.8 & 9.8 & 0.4 & 19.3 & 22.6 & 4.5 & 40.7 & 0.158 & 0.189 \\
\hline Other breakfast cereals & 3.9 & 1.1 & 6.7 & 7.3 & 3.1 & 11.5 & 6.9 & 4.3 & 9.5 & 0.438 & 0.326 \\
\hline Frozen dairy products & 6.7 & 1.4 & 12.0 & 21.1 & 10.8 & 31.4 & 36.7 & 13.9 & 59.5 & 0.001 & 0.002 \\
\hline Milks & $125.9^{\ddagger, \S}$ & 82.5 & 169.3 & 259.8 & 203.4 & 316.2 & 369.3 & 290.9 & 447.6 & $<0.0001$ & $<0.0001$ \\
\hline Creams & 7.4 & 3.6 & 11.2 & 4.6 & 1.3 & 7.9 & 3.6 & 1.4 & 5.8 & 0.369 & 0.504 \\
\hline Cheeses & $37.4^{\ddagger}$ & 26.7 & 48.2 & 32.2 & 24.3 & 40.1 & 20.2 & 13.3 & 27.1 & $<0.0001$ & $<0.0001$ \\
\hline Yogurts (natural and with fruits) & 8.0 & 1.4 & 14.5 & 18.1 & 7.4 & 28.7 & 26.3 & 11.0 & 41.5 & 0.071 & 0.072 \\
\hline Eggs & $31.5^{\ddagger}$ & 19.2 & 43.8 & 23.0 & 14.3 & 31.6 & 10.0 & 5.5 & 14.4 & 0.003 & 0.009 \\
\hline Poultry & 82.8 & 51.6 & 113.9 & 38.6 & 21.8 & 55.4 & 34.3 & 18.2 & 50.4 & 0.004 & 0.005 \\
\hline Nuts, seeds, pea & 7.4 & 3.6 & 11.2 & 6.6 & 3.4 & 9.7 & 4.3 & 1.7 & 7.0 & 0.005 & 0.012 \\
\hline Fish, shellfish & 25.3 & 12.7 & 37.9 & 9.3 & 3.7 & 15.0 & 9.6 & 2.1 & 17.2 & 0.212 & 0.313 \\
\hline Vegetables & 126.3 & 103.2 & 149.4 & 130.6 & 105.9 & 155.3 & 101.5 & 81.0 & 121.9 & 0.074 & 0.103 \\
\hline Legumes & 7.2 & -2.1 & 16.4 & 5.0 & -1.6 & 11.7 & 10.5 & 3.8 & 17.1 & 0.532 & 0.524 \\
\hline Potatoes, fried & 40.6 & 18.7 & 62.5 & 10.0 & 4.4 & 15.5 & 15.1 & 9.3 & 20.8 & 0.062 & 0.106 \\
\hline Potatoes, raw and cooked & 17.0 & 4.5 & 29.5 & 28.6 & 11.8 & 45.4 & 13.1 & 6.3 & 19.9 & 0.239 & 0.384 \\
\hline Fruit & $63.6^{\ddagger, \S}$ & 44.6 & 82.6 & 140.9 & 110.1 & 171.7 & 223.7 & 172.0 & 275.4 & $<0.0001$ & $<0.0001$ \\
\hline Sugars, syrups, preserves & 5.9 & 1.9 & 10.0 & 12.9 & 8.5 & 17.3 & 20.4 & 5.0 & 35.7 & 0.015 & 0.015 \\
\hline Savory snacks & 14.9 & 6.2 & 23.6 & 11.4 & 5.5 & 17.3 & 5.6 & 3.1 & 8.2 & 0.078 & 0.089 \\
\hline Confectionary & $6.5^{\ddagger}$ & -0.6 & 13.7 & $10.7^{\ddagger}$ & 6.6 & 14.8 & 41.1 & 23.5 & 58.6 & $<0.0001$ & $<0.0001$ \\
\hline Fruit juice & $39.2^{\ddagger, \S}$ & 10.4 & 67.9 & 123.3 & 80.7 & 165.8 & 195.5 & 108.7 & 282.2 & $<0.0001$ & $<0.0001$ \\
\hline Condiments, gravies & 27.3 & 21.3 & 33.4 & 24.9 & 18.7 & 31.1 & 28.7 & 19.9 & 37.6 & 0.965 & 0.916 \\
\hline
\end{tabular}

Note: \%E, percent energy; CI, confidence interval; Q quintile.

*Mean intake (grams/day) of food categories across quintiles of total sugars intake (\%E) were compared using a general linear model (PROC SURVEYREG) adjusted for the following covariates: Model 1, misreporting status (determined using the methods by Garriguet (2018)); Model 2, misreporting status and sex, immigrant status, weekend reference day and total energy intake. Food categories are aligned with food categories presented in the 2015 Canadian Community Health Survey (CCHS)-Nutrition with few modifications (see Supplementary Table S1 $1^{1}$ ) and expressed as grams by weight. Note that Quintiles 2 and 4 are not presented for readability. Due to a large number of non-consumption owing to single-day dietary recall data, the lower bounds of the $95 \%$ CIs for a few food categories were below zero.

The $p$-value represents the global $p$-value for a significant difference across quintiles of intake of total sugars (\%E).

${ }^{\ddagger}$ Significantly different compared with Q5 based on post hoc comparisons with Bonferroni correction, Model 2 ( $\left.p<0.05\right)$.

${ }^{\S}$ Significantly different compared with Q3 based on post hoc comparisons with Bonferroni correction, Model $2(p<0.05)$.

Similar results have been observed in Australia and the UK where they report declining trends in sugars intakes while rates of obesity continue to rise (Brand-Miller and Barclay 2017). A WHO project, which included Western European countries, Australia, the US, and China, in an analysis of energy supply and obesity, demonstrated a small effect of total fat, but the energy supply from total sugars per capita showed no relation with obesity (Silventoinen et al. 2004). They also demonstrated those with the lowest sugars intake had a higher intake of fat and subcategories of fat (Silventoinen et al. 2004). These results may be consistent with the previously observed "sugar-fat see-saw" phenomenon in Canadian adults (Wang et al. 2020) and other countries (Sadler et al. 2015).

In Canadian children aged 2-8 y and young adolescents aged 9$13 \mathrm{y}$, energy and nutrient intakes of those with the lowest total sugars intake (Q1) were fairly similar to those with intakes close to the mean $(\mathrm{Q} 3)$. A few exceptions include that Q1 had higher protein, some healthy fats and niacin, while $\mathrm{Q} 3$ had higher vitamin $\mathrm{C}$ and, in children alone, higher potassium and riboflavin. Q3 also had the highest iron and phosphorus across quintiles in young adolescents. This contrasts with those having the highest sugars intakes (Q5), who had lower intakes of several nutrients, likely due to displacement of some nutrient-dense foods with nutrient-poor foods such as confectionary, cakes and pastries, and fruit drinks. In older adolescents, comparisons between Q1 and Q3 were similar to children and young adolescents with a few additional differences, notably that Q1 had significantly lower fibre and calcium and higher sodium intakes.

According to Health Canada, Canadian children and adolescents may not be meeting their needs for potassium and fibre 
(although the interpretation of nutrient adequacy with an AI has limitations) (Health Canada 2012b). Further, many Canadian adolescents aged 9-18 y have inadequate intakes of magnesium, vitamin A, vitamin D, calcium, and phosphorous (Health Canada 2012a), while higher sodium intakes are associated with an increased risk of adverse health effects (Health Canada 2012b). Considering the nutrients highlighted by Health Canada, in Q3, children had the highest potassium and young adolescents aged 9-13 y had the highest phosphorus, while older adolescents aged 14-18 y had the highest fibre and calcium intakes. In Q1, older adolescents had the highest sodium and lowest potassium intakes. For older adolescents, the finding that sodium intakes are highest in Q1 is important as a previous study showed that adolescents with the highest sodium intakes were twice as likely to have elevated blood pressure compared with those with lower intakes, which was more pronounced in those who were overweight or obese (Yang et al. 2012). Although the pediatric literature on hypertension is limited, there is increasing evidence that obesity prevention and dietary improvements including lower sodium intakes is important to prevent and manage pediatric hypertension and to ultimately reduce the risk of hypertension and cardiovascular disease in adulthood (Dionne et al. 2017). Previous systematic reviews and meta-analyses have demonstrated that reduced salt intake resulted in small but significant reductions in systolic and diastolic blood pressure (He and MacGregor 2006). Reduced blood pressure has also been demonstrated with higher potassium intake in adolescents (Buendia et al. 2015), which was lowest in Q1 in this study. Further, the finding on higher dietary fibre intake in Q3 in older adolescents is of importance since greater consumption of dietary fibre in this age group has been associated with lower visceral adiposity and multiple biomarkers of inflammation (Parikh et al. 2012).

These findings in Canadian children and adolescents, particularly older adolescents, are similar to recent observations in Canadian adults, where those representing the mean range of total sugars intake had higher levels of many similar nutrients including fibre, calcium, vitamin C, and potassium reflected by higher fruit, milks, and yogurt consumption compared with those with either lower or higher sugars intakes (Wang et al. 2020).

Few studies have examined the association between added or free sugars intake and micronutrient intakes. An American study demonstrated a threshold of added sugars intake above which there was an increase in the prevalence of inadequate intakes for calcium, magnesium, and vitamin D among children and adolescents However, even at the lower deciles of added sugars, large percentages of the population were below the estimated average requirement (EAR) for these nutrients, suggesting that adequate intakes of these nutrients are difficult to achieve independent of added sugars intake (Fulgoni et al. 2019). A study in Australian children and adolescents found a micronutrient dilution effect only at very high free sugars takes defined as $>20 \% \mathrm{E}$, a level that was exceeded by those children and adolescents in Q5. The Australian study also found that peak intakes of most micronutrients were observed between $0-15 \% \mathrm{E}$ and meeting the WHO $10 \%$ E cut-off was associated with limited improvement in micronutrient adequacy (Wong et al. 2019), which supports the present study in which children and adolescents in Q1 and Q3 (with average free sugars intakes ranging from $5-13 \% \mathrm{E}$ ) were fairly similar in intakes of micronutrients. The micronutrient dilution theory has not been supported by other research and instead is driven by caloric intake (Gibson 2007; Marriott et al. 2010).

Overall, in this study, children and young adolescents who consume low intakes of total sugars (Q1) had similar nutrient intakes to those with sugars intakes close to the mean $(\mathrm{Q} 3)$ with a few exceptions (e.g., lowest potassium in Q1 or lower niacin in Q3), which may be relevant if there is concern of inadequacy. However, children and adolescents with the highest total sugars intakes (Q5) had the lowest intakes of nutrients such as niacin, folate, and zinc, as well as protein and fats. Older adolescents show a few notable differences where those in Q3 had better intakes of some key nutrients highlighted by Health Canada (fibre, calcium, sodium), which is similar to what has previously been observed in Canadian adults. Older adolescents may be benefiting from consumption of nutrient-dense sugars-containing foods such as fruit and milks, which provide dietary fibre, calcium, and potassium, while displacing foods high in sodium. Therefore, the findings on nutrient intakes across quintiles of total sugars intake should be interpreted in concert with recommendations, such as the WHO guideline to reduce intake of free sugars to $<10 \% \mathrm{E}$ and Health Canada's identification of nutrients of concern (for adequacy or excess consumption).

\subsection{Food categories among Canadian children and adolescents}

The food categories that principally differed between those with the highest (Q5) compared with lower sugars intakes (Q1 and Q3) were higher intakes of confectionary and fruit juice and lower intakes of pasta, rice, cereal grains and flour, and margarine. When compared only to Q1, Q5 had higher fruits, milks, and yogurts, as well as sugars and syrups, fruit drinks, cakes and pastries, cookies and granola bars, and frozen dairy, and lower cheese, eggs, and poultry. In Q3, the only food categories that differed compared with Q1 were fruits and milks, with the addition of yogurts in children, sugars and syrups in young adolescents, and fruit juices in older adolescents. Interestingly, there were no significant differences between quintiles of total sugars intakes in consumption of vegetables, legumes, nuts and seeds, fish, breads, cereals, and savoury snacks. Differences between food categories highlight that Q5 had greater intakes of foods that are lower in nutrient density (e.g., confectionary, cakes), and lower intakes of some categories that are nutrient-dense (e.g., pasta, rice, cereal grains and flours, poultry, and eggs), which may explain some nutrient findings: lower intakes of niacin, folate, and zinc, as well as protein and fat, including most subcategories of fat, compared with Q1 and Q3.

The primary contributors to the increase in total sugars intake across quintiles in all age groups were intakes of fruits and milks. However, recent evidence shows that intake of milk and alternatives has declined (Langlois et al. 2019). Further, fruit and vegetable intake in Canadian children and adolescents is below recommendations and has not improved over the past decade, if not worsened (Polsky and Garriguet 2020). Milk and alternatives are important sources of calcium in children and adolescents, yet the contribution of these foods to calcium intake has declined and nearly half of children and the majority of adolescents are below the EAR for calcium (Vatanparast et al. 2020). Moreover, increasing fruit and vegetable intake would help to address the nutrients of concern identified by Health Canada: potassium and fibre. Higher fruit and vegetable intakes are associated with reduced risk of many noncommunicable diseases including cardiovascular disease and cancer (WHO 2019), making this of high public health interest. Thus, encouraging intakes of these nutrient-dense foods, particularly in those with low sugars intakes, may have value.

In Q3, added sugars was $10 \% \mathrm{E}$, in line with the US dietary guidelines, and free sugars was $12 \% \mathrm{E}$, higher than WHO recommendations, with the difference between added and free sugars accounted for by $100 \%$ fruit juice, which corresponded to less than half a cup ( $<1$ serving of fruit). In line with Canadian dietary recommendations (Health Canada 2007, 2020), sugars-sweetened beverages intakes have declined over the past decade in Canadian children and adolescents, along with intakes of fruit juices, although total sugars intake has not changed (Langlois et al. 2019). While there is considerable scientific evidence to support an association between sugars-sweetened beverages and public health concerns, including obesity and dental caries in children and adolescents, the involvement of other sugarscontaining food sources is sparse, which may be why the WHO 
recommendation (WHO 2015) did not explore associations related to food sources of sugars. A recent systematic review of 8 prospective cohort studies in children and adolescents demonstrated no association between $100 \%$ fruit juice intake and tooth erosion or dental caries (Liska et al. 2019). With regard to adiposity, systematic reviews and meta-analyses have demonstrated no clinically significant adverse effects of $100 \%$ fruit juice consumption in children and adolescents, while some demonstrate associations with increased intakes of key nutrients (Crowe-White et al. 2016; O'Neil and Nicklas 2008; Auerbach et al. 2017). Further, the Framingham Children's Study with 10 y follow-up demonstrated that preschool consumption of $100 \%$ fruit juice ( $\geq 1$ cup/d) was associated with increased whole fruit intake and diet quality without adverse effects on BMI during childhood and into middle adolescence (Wan et al. 2020). A recent Canadian study in Guelph, Ontario, demonstrated that in children aged 1.5-5 y total, free, and added sugars intakes were not associated with the anthropometric measures, aside from a weak inverse association between free sugars intake and waist circumference (Mahajan et al. 2021). However, a longitudinal analysis found that children consistently consuming $100 \%$ fruit juice at $2 \mathrm{y}$ had greater increases in BMI z-score by $4 \mathrm{y}$ than infrequent/non-drinkers and higher odds of becoming overweight by $4 \mathrm{y}$ (Shefferly et al. 2016). No differences were observed in those consumers at $4 \mathrm{y}$ and their measures at $5 \mathrm{y}$. Although evidence on health effects beyond measures of adiposity in children are limited, evidence from systematic reviews and meta-analyses of cohort studies in adults show consumption of $100 \%$ fruit juice is not associated with harm, and instead a reduced risk of stroke mortality (D'Elia et al. 2020; Zurbau et al. 2020), metabolic syndrome (Semnani-Azad et al. 2020), and hypertension (Liu et al. 2019) when consumed at moderate doses. This recent evidence supports greater exploration into the effects of different food and beverage sources to guide public health recommendations related to sugars.

Differences in consumption of sugars-sweetened beverages, which have the most evidence to support potential harmful health effects, were only significant across quintiles of total sugars intake among adolescents (fruit drinks in younger adolescents, and soft drinks in older adolescents) where intakes were higher in Q5 compared with Q1. Therefore, strategies to reduce intake of sugarssweetened beverages may be the most relevant in adolescents, together with a better understanding of replacement strategies.

Overall, there are opportunities to make nutrient-dense snack suggestions to Canadian children and adolescents, particularly those with high sugars intakes, for example to limit confectionary, sugars, syrups and preserves, and fruit drinks, as well as certain baked goods (cakes and cookies), and instead to have more foods such as pasta, rice, and cereal grains or nuts. In older adolescents, attention may be important in both those with the lowest sugars to increase intake of fruit and milks and those with highest sugars intakes, including limiting intake of sugars-sweetened beverages. Suggestions should always be considered alongside recommendations in public health guidelines, which focus on adopting healthier dietary patterns (Health Canada 2020).

\subsection{Implications}

Our data support a shift in dietary advice away from single nutrients to focusing on promotion of nutrient-dense foods and beverages. Although global and national public health guidelines often include a focus on limiting intake of free or added sugars, the evidence identified in relation to sugars and body weight stems from prospective cohort studies on sugars-sweetened beverages. These studies demonstrate that children with the highest intakes of sugars-sweetened beverages have a greater likelihood of being overweight or obese than children with the lowest intakes, when consumed as a source of excess calories (Te Morenga et al. 2012). Recommendations focusing on nutrient density and overall dietary patterns instead of single nutrients such as sugars are particularly important among children. Many sugars-contributing foods in the diets of children, such as milks, yogurts, and fruits, play essential roles in child growth and development, as well as in maintaining a healthy body weight and reducing the risk of noncommunicable diseases (Berkey et al. 2009; Givens 2020; Mytton et al. 2014; WHO 2019). These foods are also major sources of key nutrients, including potassium, fibre, calcium, and phosphorus, which Health Canada highlights as nutrients of concern among children (Health Canada 2012b). The present analysis supports a role of some nutrientdense sugars containing foods such as fruits, milks, and yogurts in children and adolescents since those with sugars intake approximating the mean had higher intakes of these foods, along with higher intakes of key nutrients such as potassium, fibre, and calcium compared with those with the lowest sugars intakes. Further, we did not see any significant difference in energy intake or BMI between the quintiles of sugars intakes. When it comes to childhood obesity, there is insufficient evidence to support any one dietary intervention, although some evidence supports a reduction in sugars-sweetened beverages (Ebbeling et al. 2012; Muckelbauer et al. 2009). Health Canada's recommendations to help children maintain a healthy body weight go beyond identifying what foods to eat. They recommend involving children in the planning and preparation of meals, eating meals together as a family, and parents being a role model for children, in addition to identifying tips to increase physical activity and reduce sedentary time and following Canada's Food Guide (Health Canada 2019). Public health guidance focusing on nutrient-dense foods and multicomponent lifestyle interventions may be effective in the management of childhood obesity and achieving a balanced intake of nutrients.

\subsection{Strengths and limitations}

This study uses the most recent large, nationally representative sample of Canadians using a validated 24-hour dietary recall method to compare the intakes of food categories and nutrients across levels of sugars intakes in children and adolescents. This study includes the systematic calculation of added and free sugars for each individual BNS code according to the 10-step algorithm (Louie et al. 2015), most of which were assigned based on objective measures. Another strength is the stratification of the dataset by children aged 2-8 y, young adolescents aged 9-13 y, and older adolescents aged 14-18 y based on age divisions used in the dietary reference intakes and the different developmental stages and dietary patterns. Finally, all analyses were adjusted for misreporting status to reduce potential influence from recall plausibility. There are some important limitations for consideration in interpretation of the findings. First, due to restrictions in the sampling method, generalizability is limited to those within the 10 provinces, excluding those living on reserves or other Aboriginal settlements, in institutions and those $<2$ y. Second, data was analyzed from only one 24 -hour dietary recall. Thus, the data does not represent usual intake and should be interpreted with caution when comparing to dietary recommendations, although estimates from 1-day recall are considered an acceptable estimate of the mean 'usual' intake (Freedman et al. 2008). Future studies could further explore the relationships between the usual intake of sugars and dietary quality. Third, most variables were self-reported, which have limited accuracy, including the dietary intake data since energy intake tends to be underestimated (Garriguet 2018). To address this limitation, all nutrients were energy adjusted in analyses. Another limitation was the lack of health outcome data in the 2015 CCHS-Nutrition, which prohibited any health outcome-related analyses. Although a lack of association between BMI categories and sugars intake was observed in children and adolescents, caution should be applied to the interpretation of this finding, due to inconsistencies in data collection methods. Lastly, the accrual of data was potentially influenced by parent perspectives, since the interviews were completed by proxies for children aged 2-5y and both the child and parent or guardian for those aged 6-11 y. 


\section{Conclusions}

The present study compared intakes of nutrients and food categories stratified by quintiles of total sugars in Canadian children and adolescents using 24-hour dietary recalls from the 2015 Canadian Community Health Survey-Nutrition. The analysis found that Canadian children and adolescents in the lowest quintile of total sugars intake consumed 9.2-14.8\%E as total sugars, while those representing the approximate mean $(\mathrm{Q} 3)$ consumed $21.6-25.9 \% \mathrm{E}$ total sugars and those in the highest quintile (Q5), 35.5-38.1\%E as total sugars. Added sugars intakes were $4.1-5.1 \% \mathrm{E}$ in $\mathrm{Q} 1,9.3-10.3 \% \mathrm{E}$ in $\mathrm{Q} 3$ and 15.3-19.2\%E in Q5. There were no differences in energy intakes across quintiles of sugars intakes. Those with lower total sugars intake (Q1 and Q3) generally had higher protein, fat, subcategories of fat (including unsaturated and alpha-linolenic acid), niacin, folate and zinc compared with those with the highest total sugars intakes (Q5). Those with higher sugars intake generally had higher intakes of vitamin $C$ and potassium and lower intakes of sodium and saturated fat. Those with the highest total sugars intakes (Q5) had the highest intakes of confectionary, cakes and pastries, and sugars-sweetened beverages (fruit drinks in younger adolescents and soft drinks in older adolescents). These food/beverages categories, which are higher in added sugars and of lower nutrient density, may explain lower intakes of protein, healthy fats, niacin, folate, and zinc. In relation to the micronutrients of concern highlighted by Health Canada, some did not differ significantly across quintiles of total sugars intake, although in Q3 children aged 2-8 y had higher levels of potassium while adolescents aged 14-18 y had higher calcium and fibre and lower sodium. These intake levels in children and older adolescents reflected higher intakes of fruits and milks plus yogurts in children aged 2-8 y. Taken together, certain nutrient-dense food sources of sugars, such as fruit, milks, and yogurts, may help increase intakes of key nutrients of concern such as potassium in children, and potassium, calcium, and fibre in older adolescents who have low intakes of sugars. However, in children and adolescents with the highest sugars intakes, relatively nutrient-poor foods such as confectionary and, in adolescents specifically, sugars-sweetened beverages, may displace certain nutrient-dense food choices with resulting risk to adequacy of micronutrients of public health concern. Future studies should further explore added or free sugars intakes in relation to the top food contributors and how they are associated with overall dietary quality in Canadian children and adolescents to help guide public health strategies.

\section{Competing interests statement}

L.C. is a Mitacs-Elevate post-doctoral fellow jointly funded by the Government of Canada Mitacs program and the Canadian Sugar Institute (from September 2019 to August 2021). M.A. was a Mitacs-Elevate postdoctoral fellow and was jointly funded by the Government of Canada Mitacs program and Nestlé Research Center from September 2017 to September 2019. J.L.S. has received research support from the Canadian Foundation for Innovation, Ontario Research Fund, Province of Ontario Ministry of Research and Innovation and Science, Canadian Institutes of health Research (CIHR), Diabetes Canada, PSI Foundation, Banting and Best Diabetes Centre (BBDC), American Society for Nutrition (ASN), INC International Nut and Dried Fruit Council Foundation, National Honey Board (the U.S. Department of Agriculture [USDA] honey "Checkoff” program), Institute for the Advancement of Food and Nutrition Sciences (IAFNS; formerly ILSI North America), Pulse Canada, Quaker Oats Center of Excellence, The United Soybean Board (the USDA soy "Checkoff" program), The Tate and Lyle Nutritional Research Fund at the University of Toronto, The Glycemic Control and Cardiovascular Disease in Type 2 Diabetes Fund at the University of Toronto (a fund established by the Alberta Pulse Growers), The Plant Protein Fund at the University of Toronto (a fund which has received contributions from IFF), and The Nutrition Trialists Fund at the University of Toronto (a fund established by an inaugural donation from the
Calorie Control Council). He has received food donations to support randomized controlled trials from the Almond Board of California, California Walnut Commission, Peanut Institute, Barilla, Unilever/ Upfield, Unico/Primo, Loblaw Companies, Quaker, Kellogg Canada, WhiteWave Foods/Danone, Nutrartis, and Dairy Farmers of Canada. He has received travel support, speaker fees and/or honoraria from ASN, Danone, Dairy Farmers of Canada, FoodMinds LLC, International Sweeteners Association, Nestlé, Abbott, General Mills, Comité Européen des Fabricants de Sucre (CEFS), Nutrition Communications, International Food Information Council (IFIC), Calorie Control Council, and International Glutamate Technical Committee. He has or has had ad hoc consulting arrangements with Perkins Coie LLP, Tate \& Lyle, and Inquis Clinical Research. He is a member of the European Fruit Juice Association Scientific Expert Panel and former member of the Soy Nutrition Institute (SNI) Scientific Advisory Committee. He is on the Clinical Practice Guidelines Expert Committees of Diabetes Canada, European Association for the study of Diabetes (EASD), Canadian Cardiovascular Society (CCS), and Obesity Canada/Canadian Association of Bariatric Physicians and Surgeons. He serves or has served as an unpaid scientific advisor for the Food, Nutrition, and Safety Program (FNSP) and the Technical Committee on Carbohydrates of IAFNS (formerly ILSI North America). He is a member of the International Carbohydrate Quality Consortium (ICQC), Executive Board Member of the Diabetes and Nutrition Study Group (DNSG) of the EASD, and Director of the Toronto 3D Knowledge Synthesis and Clinical Trials foundation. His spouse is an employee of AB InBev. Y.(F.)W., C.D. and S.M. are employees of the Canadian Sugar Institute, a non-profit association that provides a science-based Nutrition Information Service on sugars, carbohydrates, and health, and seeks fair treatment on international trade policies and disputes. The Canadian Sugar Institute Nutrition Information Service is staffed by registered dietitians and nutrition scientists, operates at arms-length from the funding companies, and is not involved in the sales, marketing or promotion of sugars or sugars-containing products. A.(P.)N. has no conflicts of interest to disclose. The funding companies of the Canadian Sugar Institute, or other industry entities by which J.L.S. had been supported, had no role in the design of the study; in the collection, analyses, or interpretation of data; in the conclusions from the data; in the writing of the manuscript; or in the decision to publish the results. At no point from conception to publication were there any discussions and sharing of results from this study with any of the funding companies of the Canadian Sugar Institute or any other industry entities.

\section{Funding statement}

This study received no external funding. L.C. and M.A. were funded by Mitacs-Elevate Postdoctoral Fellowship Awards. J.L.S. was funded by a Diabetes Canada Clinician Scientist award, Y.(F.)W., C.D. and S.M. are employees of the Canadian Sugar Institute, a non-profit association that provides a science-based Nutrition Information Service on sugars, carbohydrates and health, and seeks fair treatment on international trade policies and disputes.

\section{Authors' contributions}

Conceptualization: L.C., Y.(F.)W., M.A. and S.M.; methodology, investigation, and formal analysis: L.C., Y.(F.)W., M.A. and A.(P.)N.; supervision: J.L.S.; writing-original draft preparation: L.C. and Y.(F.)W.; writing-review and editing: all authors. All authors have read and agreed to the published version of the manuscript.

\section{References}

Auerbach, B.J., Wolf, F.M., Hikida, A., Vallila-Buchman, P., Littman, A., Thompson, D., et al. 2017. Fruit juice and change in BMI: A meta-analysis. Pediatrics, 139(4): e20162454. doi:10.1542/peds.2016-2454. PMID:28336576. Azais-Braesco, V., Sluik, D., Maillot, M., Kok, F., and Moreno, L.A. 2017. A review of total \& added sugar intakes and dietary sources in Europe. Nutr. J. 16(1): 6. doi:10.1186/s12937-016-0225-2. PMID:28109280. 
Berkey, C.S., Colditz, G.A., Rockett, H.R., Frazier, A.L., and Willett, W.C. 2009. Dairy consumption and female height growth: prospective cohort study. Cancer Epidemiol. Biomarkers Prev. 18: 1881-1887. doi:10.1158/10559965.EPI-08-1163. PMID:19505921.

Bilodeau, M., and Brenner, D. 1999. Theory of multivariate statistics. Springer, New York, USA.

Brand-Miller, J.C., and Barclay, A.W. 2017. Declining consumption of added sugars and sugar-sweetened beverages in Australia: a challenge for obesity prevention. Am. J. Clin. Nutr. 105: 854-863. doi:10.3945/ajcn.116.145318. PMID:28275129.

Brisbois, T.D., Marsden, S.L., Anderson, G.H., and Sievenpiper, J.L. 2014. Estimated intakes and sources of total and added sugars in the Canadian diet. Nutrients, 6: 1899-1912. doi:10.3390/nu6051899. PMID:24815507.

Buendia, J.R., Bradlee, M.L., Daniels, S.R., Singer, M.R., and Moore, L.L. 2015. Longitudinal effects of dietary sodium and potassium on blood pressure in adolescent girls. JAMA Pediatr. 169: 560-568. doi:10.1001/jamapediatrics.2015.0411. PMID:25915457.

Cole, T.J., Bellizzi, M.C., Flegal, K.M., and Dietz, W.H. 2000. Establishing a standard definition for child overweight and obesity worldwide: international survey. BMJ, 320: 1240-1243. doi:10.1136/bmj.320.7244.1240. PMID:10797032.

Colley, R.C., Carson, V., Garriguet, D., Janssen, I., Roberts, K.C., and Tremblay, M.S. 2017. Physical activity of Canadian children and youth, 2007 to 2015. Health Rep. 28(10): 8-16. PMID:29044441.

Crowe-White, K., O'Neil, C.E., Parrott, J.S., Benson-Davies, S., Droke, E., Gutschall, M., et al. 2016. Impact of $100 \%$ fruit juice consumption on diet and weight status of children: an evidence-based review. Crit. Rev. Food Sci. Nutr. 56: 871-884. doi:10.1080/10408398.2015.1061475. PMID:26091353.

D’Elia, L., Dinu, M., Sofi, F., Volpe, M., and Strazzullo, P. Sinu Working Group. 2020. 100\% Fruit juice intake and cardiovascular risk: a systematic review and meta-analysis of prospective and randomised controlled studies. Eur. J. Nutr. 60: 2449-2467. doi:10.1007/s00394-020-02426-7.

Della Corte, K., Fife, J., Gardner, A., Murphy, B.L., Kleis, L., Della Corte, D., et al. 2020. World trends in sugar-sweetened beverage and dietary sugar intakes in children and adolescents: a systematic review. Nutr Rev. 79(3): 274-288. doi:10.1093/nutrit/nuaa070. PMID:32984896.

Dionne, J.M., Harris, K.C., Benoit, G., Feber, J., Poirier, L., Cloutier, L., et al. 2017. Hypertension Canada's 2017 guidelines for the diagnosis, assessment, prevention, and treatment of pediatric hypertension. Can. J. Cardiol. 33: 577-585. doi:10.1016/j.cjca.2017.03.007. PMID:28449829.

Ebbeling, C.B., Feldman, H.A., Chomitz, V.R., Antonelli, T.A., Gortmaker, S.L., Osganian, S.K., and Ludwig, D.S. 2012. A randomized trial of sugar-sweetened beverages and adolescent body weight. N. Engl. J. Med. 367: 1407-1416. doi:10.1056/NEJMoa1203388. PMID:22998339.

Freedman, L.S., Guenther, P.M., Krebs-Smith, S.M., and Kott, P.S. 2008. A population's mean Healthy Eating Index-2005 scores are best estimated by the score of the population ratio when one 24-hour recall is available. J. Nutr. 13 8: 1725-1729. doi:10.1093/jn/138.9.1725. PMID:18716176.

Fulgoni, V.L., III, Gaine, P.C., Scott, M.O., Ricciuto, L., and Difrancesco, L. 2019. Association of added sugars intake with micronutrient adequacy in US children and adolescents: NHANES 2009-2014. Curr. Dev. Nutr. 3: nzz126. doi:10.1093/cdn/nzz126. PMID:32154496.

Garriguet, D. 2018. Accounting for misreporting when comparing energy intake across time in Canada. Health Rep. 29: 3-12. PMID:29852052.

Garriguet, D., Carson, V., Colley, R.C., Janssen, I., Timmons, B.W., and Tremblay, M.S. 2016. Physical activity and sedentary behaviour of Canadian children aged 3 to 5. Health Rep. 27: 14-23. PMID:27655168.

Gibson, S.A. 2007. Dietary sugars intake and micronutrient adequacy: a systematic review of the evidence. Nutr. Res. Rev. 20: 121-131. doi:10.1017| S0954422407797846. PMID:19079865.

Givens, D.I. 2020. MILK Symposium review: The importance of milk and dairy foods in the diets of infants, adolescents, pregnant women, adults, and the elderly. J. Dairy Sci. 103: 9681-9699. doi:10.3168/jds.2020-18296. PMID:33076181.

He, F.J., and MacGregor, G.A. 2006. Importance of salt in determining blood pressure in children: meta-analysis of controlled trials. Hypertension, 48: 861-869. doi:10.1161/01.HYP.0000245672.27270.4a. PMID:17000923.

Health Canada. 2007. Eating well with Canada's food guide.

Health Canada. 2012a. Do Canadian adolescents meet their nutrient requirements through food intake alone? Cat. No. H164-112/2-2012E-PDF. Available from https:/ www.canada.ca/en/health-canada/services/food-nutrition/food-nutritionsurveillance/health-nutrition-surveys/canadian-community-healthsurvey-cchs/canadian-adolescents-meet-their-nutrient-requirements-throughfood-intake-alone-health-canada-2012.html.

Health Canada. 2012b. Do Canadian children meet their nutrient requirements through food intake alone? Cat. No. H164-112/1-2012E-PDF. Available from https://www.canada.ca/en/health-canada/services/food-nutrition/food-nutritionsurveillance/health-nutrition-surveys/canadian-community-health-surveycchs/canadian-children-meet-their-nutrient-requirements-through-foodintake-alone-health-canada-2012.html.

Health Canada. 2015. Canadian Nutrient File-About Us. Health Canada, Montréal, Que., Canada.

Health Canada. 2017. Reference guide to understanding and using the data-2015 Canadian Community Health Survey (Nutrition). Health Canada Publications, Ottawa, Ont. Available from https://www.canada.ca/en/health-canada/services food-nutrition/food-nutrition-surveillance/health-nutrition-surveys/canadian- community-health-survey-cchs/reference-guide-understanding-using-data-2015. html. [Accessed 16 April 2020.]

Health Canada. 2018. Sugars. Updated 2018-02-09. Available from https://www. canada.ca/en/health-canada/services/nutrients/sugars.html.

Health Canada. 2019. Childhood obesity. Health Canada Publications, Ottawa, Ont. Available from https://www.canada.ca/en/public-health/services/childhoodobesity/childhood-obesity.html [accessed on 20 November 2020].

Health Canada. 2020. Canada's dietary guidelines. Available from https:// food-guide.canada.ca/en/guidelines/. [Accessed 20 November 2020.]

Institute of Medicine. 2005. Dietary reference intakes for energy, carbohydrate, fiber, fat, fatty acids, cholesterol, protein, and amino acids (macronutrients). National Academy Press, Washington, DC, USA.

Irish Universities Nutrition Alliance. 2020. Ireland sugar intakes of $19 \%$ from 2017-2018 survey: National Children's Food Survey II. Irish Universities Nutrition Alliance (IUNA) https://irp-cdn.multiscreensite.com/46a7ad27/ files/uploaded/NCFS\%20II\%20Main\%20Survey\%20Report.pdf.

Langlois, K., Garriguet, D., Gonzalez, A., Sinclair, S., and Colapinto, C.K. 2019. Change in total sugars consumption among Canadian children and adults. Health Rep. 30: 10-19. PMID:30649778.

Liska, D., Kelley, M., and Mah, E. 2019. 100\% Fruit Juice and Dental Health: A Systematic Review of the Literature. Front Publ. Health, 7: 190. doi:10.3389/ fpubh.2019.00190. PMID:31355175.

Liu, Q., Ayoub-Charette, S., Khan, T.A., Au-Yeung, F., Blanco Mejia, S., de Souza, R.J., et al. 2019. Important food sources of fructose-containing sugars and incident hypertension: A systematic review and dose-response meta-analysis of prospective cohort studies. J. Am. Heart Assoc. 8: e010977. doi:10.1161/JAHA.118.010977.

Louie, J.C., Moshtaghian, H., Boylan, S., Flood, V.M., Rangan, A.M., Barclay, A.W., et al. 2015. A systematic methodology to estimate added sugar content of foods. Eur. J. Clin. Nutr. 69: 154-161. doi:10.1038/ejcn.2014. 256. PMID:25514896.

Mahajan, A., Yu, J., Hogan, J.L., Jewell, K., Carriero, A., Annis, A., et al. 2021. Dietary sugar intake among preschool-aged children: a cross-sectional study. CMAJ Open, 9: E855-E863. doi:10.9778/cmajo.20200178. PMID:34521651.

Malik, V.S., Popkin, B.M., Bray, G.A., Despres, J.P., Willett, W.C., and Hu, F.B. 2010. Sugar-sweetened beverages and risk of metabolic syndrome and type 2 diabetes: a meta-analysis. Diabetes Care, 33: 2477-2483. doi:10.2337/dc101079. PMID:20693348.

Marriott, B.P., Olsho, L., Hadden, L., and Connor, P. 2010. Intake of added sugars and selected nutrients in the United States, National Health and Nutrition Examination Survey (NHANES) 2003-2006. Crit. Rev. Food Sci. Nutr. 50: 228-258. doi:10.1080/10408391003626223. PMID:20301013.

Morrison, J.A., Friedman, L.A., and Gray-McGuire, C. 2007. Metabolic syndrome in childhood predicts adult cardiovascular disease 25 years later: the Princeton Lipid Research Clinics Follow-up Study. Pediatrics, 120: 340-345. doi:10.1542/peds.2006-1699. PMID:17671060.

Muckelbauer, R., Libuda, L., Clausen, K., Toschke, A.M., Reinehr, T., and Kersting, M. 2009. Promotion and provision of drinking water in schools for overweight prevention: randomized, controlled cluster trial. Pediatrics, 123: e661-e667. doi:10.1542/peds.2008-2186. PMID:19336356.

Must, A., Jacques, P.F., Dallal, G.E., Bajema, C.J., and Dietz, W.H. 1992. Longterm morbidity and mortality of overweight adolescents. A follow-up of the Harvard Growth Study of 1922 to 1935. N. Engl. J. Med. 327: 13501355. doi:10.1056/NEJM199211053271904. PMID:1406836.

Mytton, O.T., Nnoaham, K., Eyles, H., Scarborough, P., and Ni Mhurchu, C. 2014. Systematic review and meta-analysis of the effect of increased vegetable and fruit consumption on body weight and energy intake. BMC Publ. Health, 14: 886. doi:10.1186/1471-2458-14-886. PMID:25168465.

Newens, K.J., and Walton, J. 2016. A review of sugar consumption from nationally representative dietary surveys across the world. J. Hum. Nutr. Diet, 29: 225- 240. doi:10.1111/jhn.12338. PMID:26453428.

O'Neil, C.E., and Nicklas, T. 2008. A review of the relationship between $100 \%$ fruit juice consumption and weight in children and adolescents. Am. J. Lifestyle Med. 2: 315-354. doi:10.1177/1559827608317277.

Pan-Canadian Public Health Network. 2017. Towards a Healthier Canada Data Table. [Online.] Available from http://www.phn-rsp.ca/thcpr-vcpsre2017/table-eng.php. [Accessed November 30 2020.]

Parikh, S., Pollock, N.K., Bhagatwala, J., Guo, D.H., Gutin, B., Zhu, H., and Dong, Y. 2012. Adolescent fiber consumption is associated with visceral fat and inflammatory markers. J. Clin. Endocrinol. Metab. 97: E1451E1457. doi:10.1210/jc.2012-1784. PMID:22593589.

Perrar, I., Schmitting, S., Della Corte, K.W., Buyken, A.E., and Alexy, U. 2020. Age and time trends in sugar intake among children and adolescents: results from the DONALD study. Eur. J. Nutr. 59: 10 43-1054. doi:10.1007/s00394-019-01965-y. PMID:30976903.

Polsky, J.Y., and Garriguet, D. 2020. Change in vegetable and fruit consumption in Canada between 2004 and 2015. Health Rep. 31: 3-12. doi:10.25318/ 82-003-x202000400001-eng. PMID:32644762.

Public Health Agency of Canada. 2011. Chapter 5: Diabetes in Canada: Facts and figures from a public health perspective - Youth and children. Modified Dec 15, 2011. Available from https://www.canada.ca/en/public-health/ services/chronic-diseases/reports-publications/diabetes/diabetes-canada-factsfigures-a-public-health-perspective/chapter-5.html.

Rao, D.P., Kropac, E., Do, M.T., Roberts, K.C., and Jayaraman, G.C. 2016. Childhood overweight and obesity trends in Canada. Health Promot. Chronic Dis. Prev. Can. 36: 194-198. doi:10.24095/hpcdp.36.9.03. PMID:27670922. 
Ruiz, E., Avila, J.M., Valero, T., Del Pozo, S., Rodriguez, P., Aranceta-Bartrina, J., et al. 2016. Macronutrient distribution and dietary sources in the Spanish population: Findings from the ANIBES study. Nutrients, 8: 177. doi:10.3390/ nu8030177. PMID:27011202

Sadler, M.J., Mcnulty, H., and Gibson, S. 2015. Sugar-fat seesaw: a systematic review of the evidence. Crit. Rev. Food Sci. Nutr. 55: 338-356. doi:10.1080/ 10408398.2011.654013. PMID:24915391.

Semnani-Azad, Z., Khan, T.A., Blanco Mejia, S., De Souza, R.J., Leiter, L.A., Kendall, C.W.C., et al. 2020. Association of major food sources of fructose-containing sugars with incident metabolic syndrome: A systematic review and meta-analysis. JAMA Netw. Open, 3: e209993. doi:10.1001/jamanetworkopen.2020.9993. PMID:32644139.

Shefferly, A., Scharf, R.J., and Deboer, M.D. 2016. Longitudinal evaluation of $100 \%$ fruit juice consumption on BMI status in 2-5-year-old children. Pediatr. Obes. 11: 221 -227. doi:10.1111/ijpo.12048. PMID:26110996.

Silventoinen, K., Sans, S., Tolonen, H., Monterde, D., Kuulasmaa, K., Kesteloot, H., et al. 2004. Trends in obesity and energy supply in the WHO MONICA Project. Int. J. Obes. Relat. Metab. Disord. 28: 710-718. doi:10.1038/sj.ijo.0802614. PMID:15007395.

Stanhope, K.L. 2016. Sugar consumption, metabolic disease and obesity: The state of the controversy. Crit. Rev. Clin. Lab. Sci. 53: 52-67. doi:10.3109/ 10408363.2015.1084990. PMID:26376619.

Statistics Canada. 2015. Canadian Community Health Survey-Nutrition (CCHS). Detailed Information for 2015. Available from https://www23.statcan.gc.ca/ imdb/p2SV.pl?Function=getSurvey\&SDDS=5049. [Accessed 16 April 2020.]

Statistics Canada. 2017. 2015 Canadian Community Health Survey (CCHS)Nutrition. User Guide. Statistics Canada, Ottawa, Ont., Canada.

Statistics Canada. 2018. Canadian Community Health Survey-Nutrition: Public Use Microdata File, 2015. Statistics Canada, Ottawa, Ont., Canada.

Svensson, A., Larsson, C., Eiben, G., Lanfer, A., Pala, V., Hebestreit, A., et al. 2014. European children's sugar intake on weekdays versus weekends: the IDEFICS study. Eur. J. Clin. Nutr. 68: 822-828. doi:10.1038/ejcn.2014.87. PMID:24824016.

Te Morenga, L., Mallard, S., and Mann, J. 2012. Dietary sugars and body weight: systematic review and meta-analyses of randomised controlled trials and cohort studies. BMJ, 346: e7492. doi:10.1136/bmj.e7492. PMID:23321486.

United States Department of Health and Human Services and United States Department of Agriculture. 2016. 2015-2020 Dietary Guidelines. Available from http://health.gov/dietaryguidelines/2015/guidelines/.
USDA. 2019. AMPM-USDA Automated Multiple-Pass Method. United States Department of Agriculture, Washington, DC, USA.

Vatanparast, H., Islam, N., Patil, R.P., Shafiee, M., and Whiting, S.J. 2020. Calcium intake from food and supplemental sources decreased in the Canadian population from 2004 to 2015. J. Nutr. 150: 833-841. doi:10.1093/ jn/nxz318. PMID:31891395.

Wan, L., Jakkilinki, P.D., Singer, M.R., Bradlee, M.L., and Moore, L.L. 2020. A longitudinal study of fruit juice consumption during preschool years and subsequent diet quality and BMI. BMC Nutr. 6: 25. doi:10.1186/s40795-02000347-6. PMID:32467768.

Wang, Y.F., Chiavaroli, L., Roke, K., Diangelo, C., Marsden, S., and Sievenpiper, J. 2020. Canadian adults with moderate intakes of total sugars have greater intakes of fibre and key micronutrients: results from the Canadian Community Health Survey 2015 public use microdata file. Nutrients, 12: 1124. doi:10.3390/ nu12041124. PMID:32316582

WHO. 2006. WHO Multicentre Growth Reference Study Group. WHO Child Growth Standards: Length/height-for-age, weight-for-length, weight-forheight and body mass index-for-age: Methods and development. World Health Organization, Geneva. Available from www.who.int/childgrowth/ standards/technical_report/en. [Accessed 12 August 2020.]

WHO. 2015. Guideline: Sugars intake for adults and children. Geneva, Switzerland

WHO. 2019. Increasing fruit and vegetable consumption to reduce the risk of noncommunicable diseases. [Updated 11 February 2019.] www.who.int/ elena/titles/fruit_vegetables_ncds/en/. [Accessed 17 October 2020.]

Wong, T.H.T., Mok, A., Ahmad, R., Rangan, A., and Louie, J.C.Y. 2019. Intake of free sugar and micronutrient dilution in Australian children and adolescents. Eur. J. Nutr. 58: 2485-2495. doi:10.1007/s00394-018-1801-3. PMID:30066176.

Yang, Q., Zhang, Z., Kuklina, E.V., Fang, J., Ayala, C., Hong, Y., et al. 2012. Sodium intake a nd blood pressure among US children and adolescents. Pediatrics, 130: 611-619. doi:10.1542/peds.2011-3870. PMID:22987869.

Zurbau, A., Au-Yeung, F., Blanco Mejia, S., Khan, T.A., Vuksan, V., Jovanovski, E., et al. 2020. Relation of different fruit and vegetable sources with incident cardiovascular outcomes: a systematic review and meta-analysis of prospective cohort studies. J. Am. Heart Assoc. 9: e017728. doi:10.1161/JAHA.120.017728. PMID:33000670. 